\title{
Introdução ao estudo das craniotomias ântero-laterais e osteotomias associadas
}

\author{
Marcos Augusto Stávale Joaquim ${ }^{1}$, Hector Navarro Cabrera² \\ Instituto Neurociências. São Paulo, SP, Brasi
}

\begin{abstract}
RESUMO
Neste artigo estão integrados conceitos elementares no aprendizado das vias de acesso ântero-laterais do crânio, de acordo com uma sistematização baseada na associação progressiva de osteotomias às craniotomias rotineiras. Um roteiro de estudos sobre estes acessos é exposto com as respectivas recomendações de leitura.
\end{abstract}

\section{PALAVRAS-CHAVE}

Craniotomia. Osteotomia. Cirurgia, técnicas.

\section{ABSTRACT}

An introduction to the study of osteotomies associated to anterolateral craniotomies To systematize progressive association of regional osteotomies into the classical and basic anterolateral craniotomies. The basic literature was reviewed and inicated as a direction to elementary studies about this approaches.

\section{KEY WORDS}

Craniotomy. Osteotomy. Surgery, techniques.

\section{Introdução}

Por intermédio da leitura deste texto básico, pode-se ter a compreensão da evolução anatômica das craniotomias ântero-laterais e, ao mesmo tempo, acesso às principais referências na literatura sobre as osteotomias utilizadas e seus objetivos anatomocirúrgicos. Objetivase, assim, sistematizar o raciocínio da escolha de tais osteotomias durante a fase de introdução à técnica neurocirúrgica na formação básica desta especialidade.

\section{Craniotomias frontais}

As craniotomias frontais são procedimentos convencionais. Podem ser unilaterais ou bilaterais e atingir ou não a linha média do crânio. Usualmente, a sua extensão lateral e inferior alcança uma trepanação situada posteriormente à apófise orbitária externa, ou processo zigomático do osso frontal, e anteriormente à sutura esfenofrontal, ocupando, portanto, a região pré-pterional. A técnica pré-pterional exclusiva foi sistematizada por Brock e cols. ${ }^{7}$, em 1978, como alternativa à expansão temporal da craniotomia.

A extensão medial da craniotomia encontra a crista frontal interna, lâmina óssea mediana de base alargada que termina pouco antes do início da crista-galli (figura 11).

As craniotomias frontais são amplamente utilizadas para o tratamento de lesões localizadas na fossa craniana anterior, na órbita, na região etmoidal e na região selar. Recentemente, sua utilização estendeu-se às lesões clivais. Extensões basais etmoidais profundas da craniotomia frontal bilateral, como o acesso transbasal

\footnotetext{
1 Neurocirurgião dos Hospitais Albert Eisntein e Sírio-Libanês. Doutor em Medicina pela Universidade de São Paulo (USP) e Coordenador do curso de pós-graduação em Neurointensivismo do Instituto de Ensino e Pesquisa do Hospital Sírio-Libanês. São Paulo, SP.

2 Neurocirurgião do Hospital Sírio-Libanês. Médico-assistente do Serviço de Neurocirurgia do Hospital das Clínicas da Faculdade de Medicina da Universidade de São Paulo (HC-FMUSP). São Paulo, SP.
} 
ao clivus, foram revistas por Sekhar e cols. ${ }^{51}$, em 1992 , freqüentemente com osteotomias adicionais.

Aneurismas complexos da artéria comunicante anterior foram abordados por meio de uma craniotomia bifrontal por vários neurocirurgiões, às vezes ampliando-se a craniotomia bifrontal para os rebordos orbitários superiores, à semelhança da técnica frontoorbitária de Jane e cols. ${ }^{31}$, publicada em 1982.

\section{Craniotomias frontoorbitárias}

Estes procedimentos dizem respeito às extensões orbitárias das craniotomias frontais, que permitem melhor manipulação da órbita ou ampliam o campo operatório de trabalho subfrontal. A remoção dos rebordos orbitários lateral e superior e de parte do teto da órbita, em conjunto com o retalho ósseo frontal, amplia a exposição do conteúdo orbitário, diminui a retração necessária do lobo frontal e aproxima a região do ápice orbitário da superfície do campo cirúrgico.

A sistematização contemporânea clássica dessa via foi apresentada por Jane e cols. ${ }^{31}$, em 1982, como uma modificação do método antigo, denominada de abordagem supra-orbitária e indicada para a exposição de massas subfrontais e da órbita, bem como de aneurismas do complexo da artéria comunicante anterior. Tecnicamente, utilizam-se uma incisão bicoronária e o rebatimento subperiostal do tegumento, mantendo-se a continuidade do pericrânio com a periórbita ao nível do rebordo orbitário, onde o nervo e os vasos supraorbitários são mantidos intactos e liberados de seu forame ou fenda. O primeiro orifício de trepanação é realizado acima da sutura nasofrontal, atravessando-se o seio frontal, e o segundo, atrás do processo zigomático do osso frontal. A margem inferior da parte orbitária do retalho ósseo é delineada seccionando-se o teto da órbita de cima para baixo com serra de Gigli ou broca, protegendo-se a periórbita, que deve ser mantida intacta, com uma espátula. A margem superior da craniotomia é delineada com craniótomo, e uma ressecção adicional, osteoplástica ou não, do teto órbita, pode ser realizada (figura 1). Esse retalho ósseo é recolocado após o procedimento, precedido da oclusão do seio frontal exposto pela sutura de um enxerto pediculado de pericrânio frontal à dura-máter. Essa craniotomia foi denominada, em sistematização prévia, de acesso frontoorbitário. Adicionalmente, sua execução bilateral em retalho duplo foi utilizada para a correção da cranioestenose associada à oclusão precoce da sutura metópica, em casos graves de trigonocefalia com a rima supra-orbitária lateral anormal. A craniotomia frontoorbitária também foi utilizada para o tratamento cirúrgico do exoftalmo.

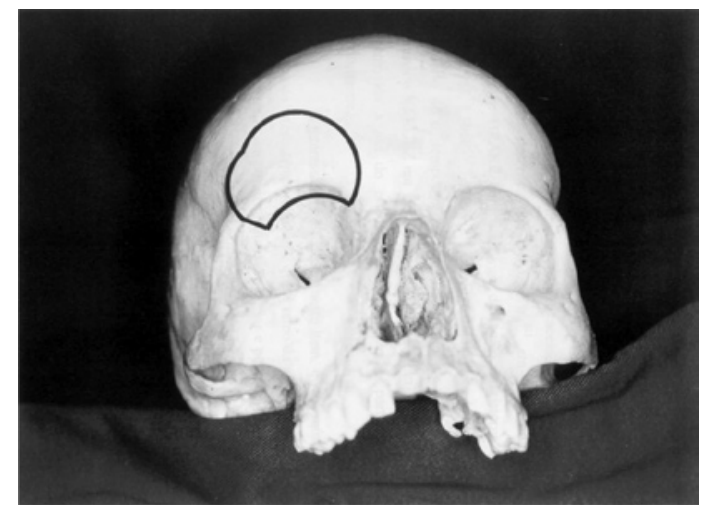

Figura 1 - Demonstração da craniotomia que permite o acesso frontoorbitário com retalho ósseo único. Variações nas suas dimensões são realizadas com facilidade.

Cophignon e cols. ${ }^{11}$, em 1983, ampliaram o acesso transbasal ao clivus removendo os rebordos orbitários mediais até o dorso nasal e duplicando inferiormente o ângulo de exposição basal da região do seio esfenoidal.

\section{Craniotomias temporais}

As craniotomias temporais, usualmente, destinamse às lesões situadas dentro ou sob o compartimento da fossa média ou a lesões mediais que incluem as regiões do seio cavernoso e do hiato tentorial adjacente, incluindo o mesencéfalo e o setor posterior do polígono de Willis. Poletti ${ }^{42}$, em 1989, propôs uma pequena craniotomia temporoesfenoidal para se abordar aneurismas em todo o polígono de Willis, por meio de ampla dissecção cisternal.

A craniotomia temporal é freqüentemente utilizada em combinação com técnicas pré ou subtemporais para o acesso aos compartimentos incisurais médio e anterior, conforme se nota nas publicações de Drake ${ }^{18}$ para a cirurgia da região da cisterna interpeduncular, em 1961. Também é utilizada, além da convencional abordagem do próprio lobo temporal, para o tratamento de lesões orbitárias. Por esse acesso, pode ser removida a asa do esfenóide anteriormente, e parte da pirâmide petrosa, posteriormente.

É interessante considerar, neste item, que o músculo temporal tem seus vasos derivados da artéria temporal média, que é ramo da artéria temporal superficial, e de ramos das artérias temporais profundas anterior e posterior, ramos da artéria maxilar. As artérias meníngeas médias formam anastomoses com as artérias temporais profundas por via intradiplóica, e com as artérias temporais superficiais, por via intramuscular, conforme Casanova e cols. ${ }^{9}$ expuseram em 1986. 
A artéria temporal média comunica-se com as artérias temporais profundas anterior e posterior, e a artéria temporal superficial forma uma rede horizontal com as artérias occipital, supraorbitária e supratroclear. $\mathrm{Na}$ técnica de Oikawa e cols. ${ }^{38}$, preserva-se grande parte dessa rede vascular e da inervação muscular, além de obter-se melhor exposição inferior.

\section{Craniotomias frontotemporais}

A craniotomia frontotemporal diz respeito ao retalho ósseo homônimo removido para a exposição ântero-lateral da base do crânio. Trata-se de uma técnica clássica e que vem progressivamente evoluindo com relação ao local das osteotomias e à associação de outras remoções ósseas compartimentalizadas, das quais a mais conhecida é a esfenoidectomia convencional. Há ampliações anteriores, posteriores ou basais dessa craniotomia, realizadas por diversos autores.

A craniotomia pterional é o acesso frontotemporal mais utilizado em neurocirurgia convencional, pois proporciona acesso à base do crânio e principalmente aos vasos do polígono de Willis. Essa técnica é utilizada como referência para a avaliação das vantagens obtidas com a realização de osteotomias adicionais ou craniotomias expandidas. Essa abordagem foi modificada por Dandy $^{12}$, em 1941, para a operação de aneurismas do complexo da artéria comunicante anterior. Foi redefinida por Yasargil e cols. ${ }^{63}$, em 1975, associando-se a remoção parcial da asa do esfenóide e, se necessário, da parte do teto orbitário.

De acordo com a técnica convencional, o paciente é colocado em posição supina, com a cabeça posicionada em nível acima do átrio direito e rodada $30^{\circ}\left(15^{\circ}\right.$ a $\left.45^{\circ}\right)$ para o lado oposto à craniotomia. A incisão arciforme estende-se posterior e paralelamente à linha de transição do couro cabeludo com a pele glabra, desde a borda superior do arco zigomático até a linha média. Seguem-se a abertura e o descolamento do tegumento no plano subperiostal até a parte inferior da aponeurose superficial do músculo temporal, que é incisada transversalmente e rebatida em conjunto com o retalho superficial. Tal manobra de dissecção interfacial visa à preservação do ramo frontal do nervo facial, conforme descrito por Yasargil em 1984. Em seguida, rebate-se o músculo temporal inferiormente de maneira a expor o ptérion (figura 2).

Uma craniotomia quadrangular com poucas trepanações e uso do craniótomo é realizada (figura 3).

Essa craniotomia permite manipulação cisternal homolateral, conforme discutem os autores citados acima, mas conforme publicações adicionais de Sugita e cols. ${ }^{57}$, de 1979 , pode incluir a região das cisternas

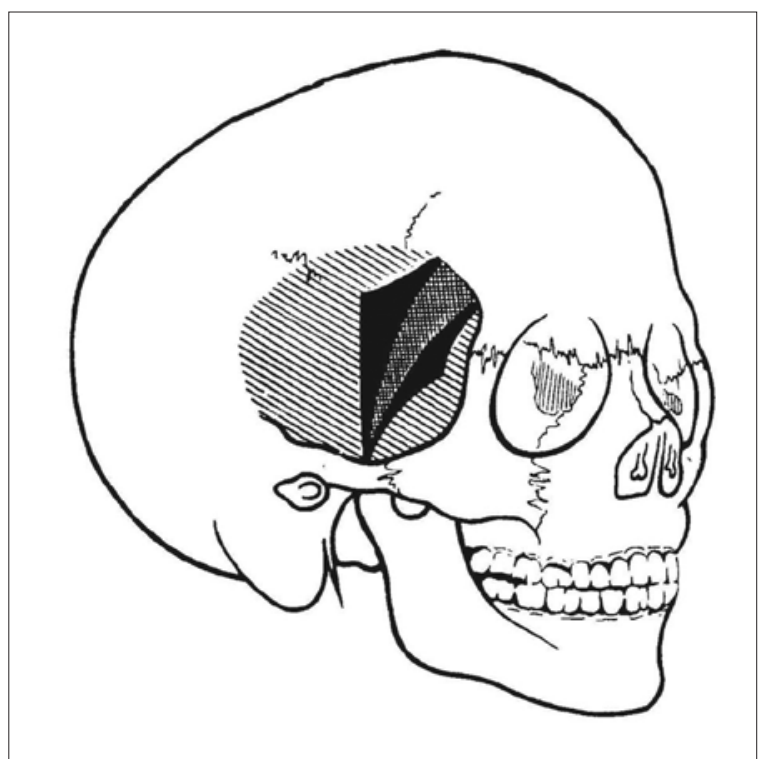

Figura 2 - Incisão rotineira da aponeurose do músculo temporal de modo a preservar o ramo frontal do nervo facial. O segmento inferior à incisão é rebatido em conjunto com o retalho tegumentar.

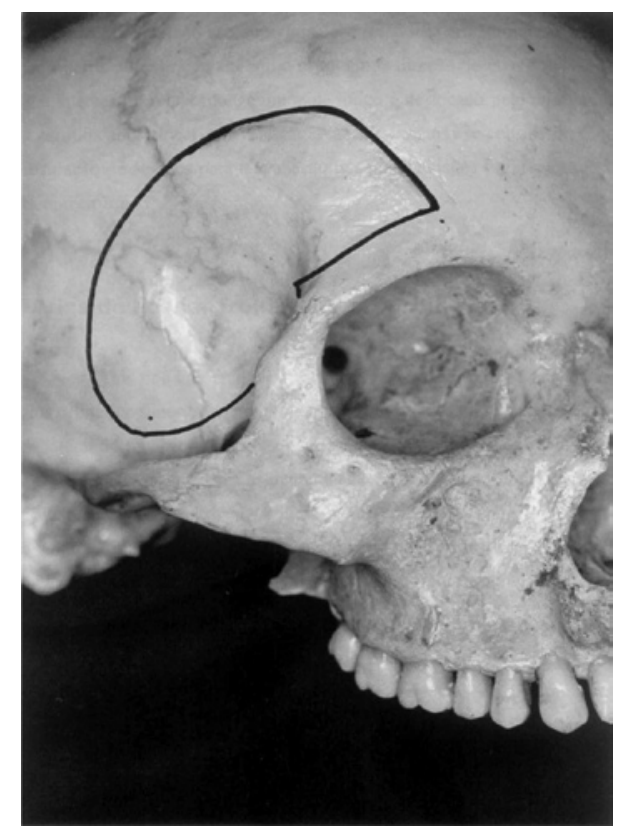

Figura 3 - Representação da craniotomia frontotemporal para o acesso pterional. As trepanações podem variar em posição e número.

interpeduncular e das asas da cisterna ambiens. A região da cisterna interpeduncular pode também ser abordada, além do acesso transsilviano, por vias subtemporal ou prétemporal utilizando-se essa craniotomia ampliada posteriormente, fato notado por Chou e cols. ${ }^{10}$, em 1974. Há também a possibilidade de se abordar lesões vasculares da cisterna interpeduncular através da via frontotemporal pterional. Em relação ao acesso subtemporal preconizado 
por Drake ${ }^{19}$, em 1968, a craniotomia pterional permite menor retração do lobo temporal, melhor apreciação da anatomia cisternal, menor possibilidade de lesão dos nervos oculomotor e troclear e a possibilidade da oclusão de outros aneurismas eventualmente presentes. Entretanto, este acesso é parcialmente obstruído pelas artérias carótida interna e comunicante posterior. Assim, três espaços são apresentados para se alcançar a região retrosselar: o triângulo optocarotídeo, o espaço retrocarotídeo medial e o espaço retrocarotídeo lateral, o último entre a artéria comunicante posterior e o nervo oculomotor. Eventualmente, poderia ser usado o espaço "suprabifurcação", definido por Kobayashi e cols. ${ }^{34}$ em 1983.

Tanaka e cols. ${ }^{58}$, em 1995, discutiram o estudo dos acessos e concluíram que os ângulos entre o eixo dos clipes dos aneurismas e o eixo ântero-posterior nem sempre indicam a real direção do acesso, pois a direção do acesso visual e da aplicação do clipe não é superponível, o lado da craniotomia e a orientação direita-esquerda do cirurgião alteram o resultado, a direção do eixo do clipe altera-se após sua liberação do aplicador, e um clipe longo é deslocado pelo encéfalo ou pela artéria carótida após aliviar-se a retração. Naquela pesquisa considerou-se o conceito de mensuração de ângulos para a avaliação das possibilidades estratégicas fornecidas pelo campo cirúrgico.

\section{Craniotomias frontotemporoorbitárias}

Tais tipos de craniotomias adicionam, ao retalho ósseo, partes dos rebordos orbitários superior e lateral e partes do teto da órbita. Quando se adiciona a metade lateral do rebordo orbitário superior e a metade superior do rebordo orbitário lateral, a técnica é arbitrariamente denominada de frontotemporoorbitária lateral, e quando a craniotomia se estende à linha média em suas relações orbitárias, estendendo-se ou não no rebordo orbitário lateral até o nível da margem superior do arco zigomático, a técnica é denominada de frontotemporoorbitária completa (figura 4). Tais craniotomias aumentam a exposição do alvo cirúrgico à visão microscópica, e a área de manipulação do instrumental aproxima o cirurgião de seu objetivo, diminuindo a distância do alvo até a superfície do campo operatório, e minimiza a retração cerebral, além de oferecer acesso adicional para a exposição orbitária. Esses métodos operatórios, que adicionam ao acesso pterional previamente descrito a remoção de partes da rima e do teto orbitários e da asa do esfenóide, facilitam a exposição da região clinóidea anterior, que inclui a bifurcação carótido-oftálmica, a porção anterior do seio cavernoso, o canal óptico e a região orbitoesfenoidal medial.

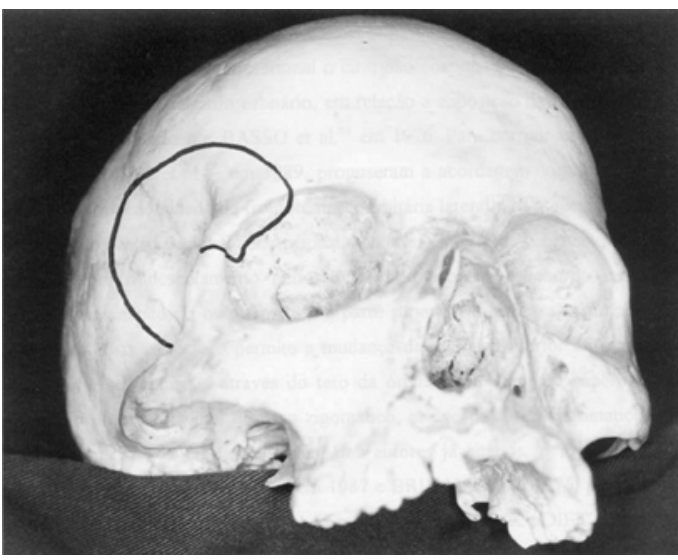

Figura 4A-Craniotomia frontotemporoorbitária lateral.

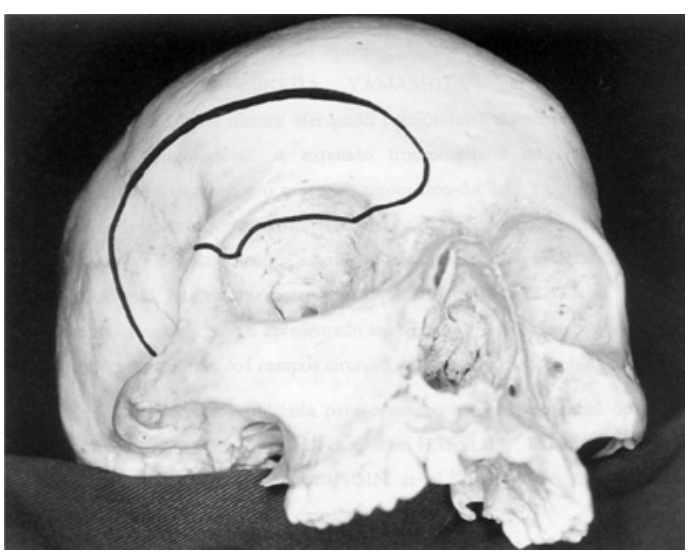

Figura 4B - Craniotomia frontotemporoorbitária completa.

$\mathrm{Na}$ abordagem pterional, o cirurgião costuma ser limitado pelas partes superior e lateral do rebordo orbitário, em relação à exposição da região clinóidea e da órbita. Para corrigir essa limitação de exposição, Smith e cols..$^{55}$, em 1989, propuseram a abordagem "orbitocranial”, que mais tarde foi denominada de frontotemporoorbitária lateral. Tal técnica implica a realização do acesso pterional convencional modificado, pois o descolamento periostal continua com o descolamento periorbitário e são expostos o rebordo orbitário, o processo zigomático do osso frontal e a parte superior do processo frontal do osso zigomático. Essa exposição permite a mudança da margem inferior da craniotomia, que passa a ser realizada através do teto da órbita na sua porção superolateral e através do processo frontal do osso zigomático, abaixo da sutura zigomaticofrontal. Essa manipulação da órbita tem, além dos autores já citados, o merecimento dos estudos adicionais de Al Mefty ${ }^{1}$, em 1987.

Após a craniotomia pterional apresentada por Yasargil e cols. ${ }^{63}$, em 1975, e a modificação orbitocranial apresentada por Smith e cols. ${ }^{55}$ em 1989, foram 
desenvolvidas modificações, efetuando craniotomias diferentes e associando a elas o acesso temporopolar, também denominado de pré-temporal. A extensão frontoorbitária da craniotomia pode aproximar-se da linha média, e o processo zigomático do osso frontal é excisado na base, ao nível da borda superior do arco zigomático, facilitando a retração posterior do pólo temporal e o acesso temporopolar e dispensando a remoção zigomática ampliada. A clinoidectomia anterior foi associada em alguns casos. É interessante notar que na publicação de Ikeda e cols. ${ }^{30}$, de 1991, o desenho das vias de acesso é apresentado em forma de setas triangulares simulando parcialmente a morfologia dos campos cirúrgicos cônicos em secção longitudinal. Tal técnica é utilizada para o acesso à região do canal óptico e da fissura orbitária superior, conforme preconizaram Hassler e cols. ${ }^{29}$, em 1985, e Yasargil e cols. ${ }^{64}$, em 1975, que associaram osteotomias esfenoidais variáveis à craniotomia.

A publicação similar de Fujitsu e cols. ${ }^{22}$, de 1986, sobre o acesso frontotemporoorbitário lateral destaca o seu uso para a abordagem de lesões da cisterna da lâmina terminalis. $\mathrm{Na}$ apresentação gráfica da técnica, parece existir uma maior remoção do tecido ósseo continente da órbita, permitindo retração de seu conteúdo para ampliar a exposição em direção ao esplancnocrânio. Considerou-se a ampliação medial do componente frontoorbitário da craniotomia, ao que denominamos craniotomia frontotemporoorbitária completa, se comparada com a craniotomia frontotemporoorbitária lateral. Trata-se da junção do acesso pterional convencional ao acesso de Jane e cols. ${ }^{31}$, descrita em 1982. No nosso meio, essa craniotomia foi utilizada por Cabrera e cols. ${ }^{8}$, em 1985, para a ressecção de volumosos meningiomas de asa no esfenóide. Em 1987, o estudo dessa técnica, denominada por Al Mefty ${ }^{1}$ de abordagem "supra-orbitária-pterional", foi apresentado. Nessa modalidade de osteotomia craniana, a incisão tegumentar estende-se à linha temporal superior contralateral, para que seja possível uma exposição médio-basal suficiente para a extensão da craniotomia à linha média. As trepanações são realizadas sobre o seio frontal e na junção frontoesfenoidal, a última expondo, na sua parte superior, a dura-máter e, na inferior, a periórbita. A terceira trepanação é temporal e a complementação da secção é realizada por craniótomo. Tal técnica presta-se para a ressecção de lesões mediais da asa do esfenóide, parasselares, e mesmo através da lâmina terminalis para o acesso às regiões selar e suprasselar. Os autores consideraram que a remoção do retalho ósseo em bloco único permite melhor reconstrução, ponto importante em cirurgias da base do crânio.

\section{Vias de acesso à órbita}

A cavidade orbitária pode ser alcançada através do neurocrânio, do viscerocrânio, ou por acessos combinados. Após a determinação da topografia da lesão, procede-se à escolha entre as técnicas de abordagem (transcranianas frontal, frontotemporal, frontoorbitária e frontotemporoorbitária), ou através dos acessos orbitários laterais (orbitário e orbitozigomático).

A composição óssea da órbita inclui vários ossos que se unem delimitando uma cavidade cônica de ápice posterior relacionado ao canal óptico e às fissuras orbitárias. O canal óptico situa-se entre as raízes da asa menor do esfenóide e possui aproximadamente $5 \mathrm{~mm}$ a $10 \mathrm{~mm}$ de comprimento e $5 \mathrm{~mm}$ de diâmetro. $\mathrm{O}$ teto do canal tem, em média, $2 \mathrm{~mm}$ de espessura. Sua abertura proximal é formada pelo ligamento falciforme. Medialmente, situa-se o seio esfenoidal e, lateralmente, o processo clinóide anterior, que pode ser pneumatizado e comunicar-se com o seio esfenoidal. O segmento intracraniano do nervo óptico tem aproximadamente $15 \mathrm{~mm}$ de extensão e penetra no canal óptico em conjunto com a pia-máter e com a dura-máter, esta em continuidade com a periórbita. A irrigação neural dá-se pela artéria oftálmica e pelas artérias ciliares. O ânulo de Zinn, apical, insere cinco dos seis músculos intraorbitários e é atravessado pelo nervo óptico e pela artéria oftálmica, além dos nervos que trafegam pelo forame oculomotor.

As técnicas de abordagem transcraniana destinamse principalmente a tumores apicais, ou mediais ao nervo óptico, ou a tumores grandes, principalmente os que invadem a fossa craniana anterior.

Quando se pretende ressecar massas localizadas no ápice da órbita, ou que invadem compartimentos adjacentes a esta, osteotomias adicionais são necessárias. As remoções das paredes superior e lateral da órbita, das asas esfenoidais, do canal óptico e do processo clinóide anterior permitem tais exposições. Quando se removem as paredes lateral, superior e posterior da órbita, a reconstrução é necessária para prevenir o enoftalmo, segundo orientação de Derome e cols. ${ }^{15}$, em publicação de 1978. O exoftalmo pulsátil geralmente não é identificado na literatura. Observamos que, opostamente, em ressecções mais extensas, a reconstrução do teto da fossa infratemporal, como descrito por Pellerin e cols. ${ }^{36}$ em 1984, geralmente não é necessária, o que revela as diferentes necessidades de reconstrução após a cirurgia em áreas distintas da base do crânio.

Tumores malignos da glândula lacrimal podem necessitar exenteração em bloco da órbita, envolvendo seus limites ósseos, que podem ser reconstruídos. Retalhos musculares pediculados, esternocleidomastóideos ou deltopeitorais, podem ser usados para preencher a 
área esvaziada, assim como retalhos pediculados por meio de técnicas de anastomose microcirúrgica.

Hammer e cols. ${ }^{28}$, em 1994, utilizaram o acesso transcraniano pterional para tumores orbitários, combinado com a ressecção do osso zigomático, da asa do esfenóide e do rebordo orbitário superior, considerando esse o procedimento de escolha para neoplasias orbitárias, e procedendo à reconstrução posterior com miniplacas de titânio.

A técnica de exposição lateral proposta por Kröenlein, em 1889, sofreu modificações, por exemplo, as apresentadas por Maroon e cols. ${ }^{36}$ em 1985. As modificações constam basicamente da utilização da técnica microcirúrgica e das osteotomias adicionais utilizadas, que se estendem nas direções frontal, temporal, zigomática, maxilar e esfenoidal. $\mathrm{O}$ acesso lateral convencional é utilizado para massas localizadas nos compartimentos superior, temporal e inferior da cavidade orbitária, e na parte lateral do ápice orbitário. O acesso orbitozigomático é utilizado para exposição de maior área lateral na órbita.

A técnica de abordagem medial é utilizada para tumores mediais ao nervo óptico e não profundamente situados, assim como para descompressão do nervo óptico.

\section{Associação da remoção do arco zigomático e do corpo do osso zigomático}

A seção cirúrgica do arco zigomático foi considerada para diminuir a retração cerebral durante a abordagem da cisterna interpeduncular por uma craniotomia temporal, por Pitelli e cols. ${ }^{37}$, em 1986, no Brasil. Esses autores removeram o arco zigomático sob a craniotomia, permitindo que o eixo do campo visual pudesse ser angulado caudalmente, criando um acréscimo ao ângulo de exposição com minimização da retração da base do lobo temporal. Tal retração seria maior na abordagem subtemporal do que no acesso pterional. Essa técnica também foi utilizada para o tratamento de lesões traumáticas temporobasais, facilitando a exposição e a plástica dural. A secção zigomática também exclui, do campo visual do cirurgião, a presença do músculo temporal, que é deslocado caudalmente ${ }^{41}$ (figura 5). Tal técnica foi denominada de craniotomia temporozigomática.

Em 1985, Fujitsu e cols..$^{21}$ propuseram a abordagem temporozigomática para o acesso à região interpeduncular, também com o intuito de minimizar a retração cerebral. Tal zigomaticotomia estendia-se parcialmente ao ramo ascendente do osso zigomático, ampliando a exposição anteriormente. Para a remoção do arco zigo-

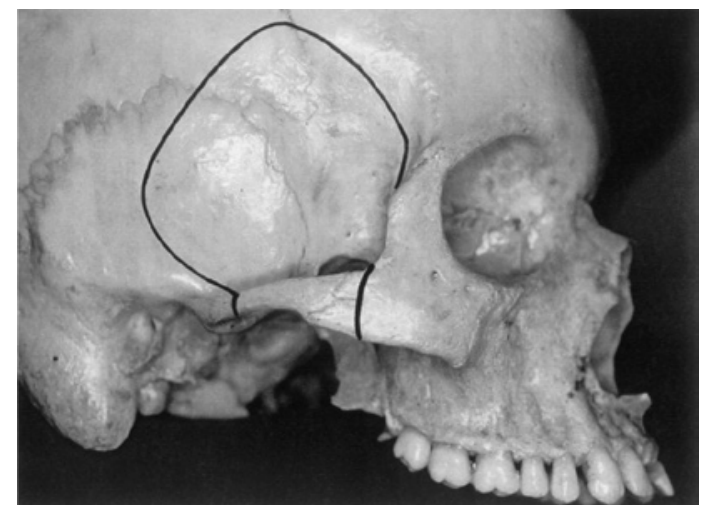

Figura 5 - Craniotomia temporozigomática. Nota-se a craniotomia exclusivamente temporal, entretanto uma craniotomia frontotemporal pode ser associada com a mesma facilidade, ampliando a exposição da região esfenoidal que constitui a parede anterior da fossa craniana média. A técnica apresentada expõe satisfatoriamente a parede inferior da fossa média.

mático, são realizadas duas incisões na fáscia temporal externa, uma anterior e uma posterior, promovendo a exposição óssea para as osteotomias, que liberam o arco zigomático, mantendo-o dentro do plano interfascial, para ser rebatido em conjunto com o músculo temporal. Tais osteotomias são corrigíveis no momento da reconstrução com facilidade, pela osteossíntese convencional com placas e parafusos.

Uma vez exposta a região da fossa zigomática, craniotomias temporais ou frontotemporais, associadas a esfenoidectomias diversas, podem ser realizadas. $\mathrm{O}$ trabalho intracraniano pode ser desenvolvido por meio da retração posterior do pólo do lobo temporal, como sistematizou $\mathrm{Sano}^{43} \mathrm{em}$ 1980, ou pela elevação da face inferior do mesmo lobo. Realiza-se sempre dissecção cisternal e ligadura de veias em ponte deste lobo.

Tal osteotomia zigomática isolada não ofereceria, aparentemente, e considerando-se apenas a estrutura óssea, um aumento significativo do ângulo de exposição basal. Entretanto, se considerarmos a permissão de manipulação muscular que essa técnica oferece, entende-se que a retração caudal do músculo temporal amplia claramente o campo cirúrgico no sentido subtemporal, fato demonstrado por Pitelli e cols..$^{37} \mathrm{~A}$ exérese do assoalho da fossa média e a abordagem do seu setor medial são facilitadas por essa técnica.

A zigomaticotomia foi incluída na cirurgia combinada da fossa infratemporal ao acesso frontotemporal e, em 1965, Samy e cols. ${ }^{46}$ propuseram o acesso transzigomático para fibromas nasofaríngeos com expansão parafaríngea. Em 1990, Al Mefty e cols. ${ }^{2}$ descreveram uma modificação da osteotomia do arco zigomático associando-a à secção do processo coronóide da mandíbula e estenderam o acesso à região subtemporal, por considerarem que certos tumores como angiofibromas e 
neurinomas ocupam a fossa infratemporal, a fossa temporal, o seio cavernoso, a órbita e a fossa esfenopalatina.

Várias técnicas foram propostas para se abordar lesões nessa localização. Algumas necessitando de grandes exposições e reconstruções, como os acessos frontotemporoorbitozigomáticos, às vezes transgredindo os seios paranasais.

Basicamente, as osteotomias restritas ao arco zigomático têm limitações em relação ao acesso da fossa infratemporal se não se manipular parcialmente o processo coronóide da mandíbula. Tumores mais extensos, obviamente, exigem mandibulectomias parciais mais amplas.

Rubini e cols. ${ }^{44}$, em 1994, propuseram que a remoção isolada do arco zigomático associada à craniotomia temporal é suficiente para lesões da fossa craniana média, particularmente de seu compartimento medial. Pode associar-se a remoção da asa do osso esfenóide e, se necessário, do processo clinóide anterior. Considera-se que os limites para a exposição extradural da fossa média são os forames oval, espinhoso e redondo e, para a exposição intradural, o espaço incisural médio. A osteotomia do assoalho da fossa média é limitada pelos forames mediais. A artéria carótida petrosa é exposta e o ápice da pirâmide pode ser removido entre o gânglio trigeminal, a cóclea, a goteira esfenopetrosa, o canal carotídeo e o canal auditivo interno, conforme a técnica apresentada por Kawase e cols. ${ }^{33}$, em 1991. Se o seio petroso e o tentório forem seccionados, pode-se visualizar a porção inferior da artéria basilar. Se outras diversas osteotomias adicionais forem executadas, consegue-se ampla exposição do clivus e do tronco cerebral.

O limite posterior do acesso transzigomático é o osso temporal. As osteotomias petrosas mediais são anteriores ao aparelho auditivo. Na literatura otorrinológica, muitos acessos ao ápice da pirâmide são descritos freqüentemente, sacrificando a audição. Hakuba e cols. ${ }^{27}$, em 1988, e Spetzler e cols..$^{56}$, em 1992, passaram a remover a arquitetura óssea petrosa retro e préauricular e dividir o seio petroso superior e o tentório, expondo o sistema vertebrobasilar e, algumas vezes, preservando a audição. Acessos transcocleares combinados que envolvem osteotomias do seio sigmóide ao clivus e do seio petroso superior ao forame magno são eventualmente utilizados quando se trabalha na fossa infratemporal após as zigomaticotomias.

Considera-se que o acesso transzigomático oferece otimização da exposição do assoalho da fossa craniana média com baixa morbidade e bons resultados estéticos e a craniotomia pterional associada permite os acessos transsilviano e subtemporal. As osteotomias adicionais permitem acessos da goteira olfatória ao meato acústico interno e do processo clinóide anterior ao forame magno.
Gabibov e cols. ${ }^{23}$, em 1994, revendo sua experiência em 40 casos de meningiomas tentoriais anteriores, utilizaram-se do acesso subtemporal sem citar a remoção zigomática, considerando, entretanto, a combinação de acessos posteriores quando há expansão infratentorial. As relações topográficas neurovasculares desses tumores são consideradas os fatores limitantes mais importantes de sua ressecção, mesmo com a evolução das vias de acesso ósseas.

Após a ressecção osteoplástica do arco zigomático, considerou-se a expansão anterior da osteotomia para a remoção completa do osso malar em conjunto com fragmentos orbitários e, às vezes, de segmentos do osso maxilar. Tal técnica aumenta a exposição ântero-lateral da base do crânio e facilita o acesso orbitomaxilar.

Embora o objetivo de minimizar a retração cerebral com o desenvolvimento do conhecimento da anatomia estimulasse as inovações atuais das abordagens para a base do crânio, incluindo a remoção do arco zigomático, a idéia de remover o osso zigomático com ou sem a rima orbitária lateral já havia sido estudada por outros cirurgiões, destacando-se os estudos de Sekhar e cols. ${ }^{49}$, de 1995, e de Kawase e cols. ${ }^{33}$, de 1991.

Esse procedimento expõe as fossas anterior, média, infratemporal, zigomática, pterigo-maxilar, a porção superior da fossa posterior, a incisura tentorial, a órbita e toda a região adjacente, permitindo a ampliação do campo de abordagem aos tumores que penetram nas cavidades craniofaciais, incluindo, em ressecções mais extensas, o espaço faríngeo lateral, a trompa de Eustáquio, os seios paranasais, e o seio cavernoso. Entretanto, tal provável vantagem dessa via de acesso jamais fora quantificada numericamente. Obviamente, o acesso a estruturas mais profundas requer osteotomias adicionais como as petrossectomias, mandibulectomias e maxilectomias.

A anatomia cirúrgica do acesso transzigomático foi estudada por Ammirati e cols. ${ }^{4}$ em 1992, com o intuito de conhecer essa via de acesso que aumentava a exposição cirúrgica e minimizava a retração cerebral.

As dissecções tegumentares em geral poupam os ramos do nervo facial, à semelhança da dissecção interfacial temporal de Yasargil ${ }^{62}$ descrita em 1984. O arco zigomático é exposto no plano subperiostal e as inserções da musculatura temporal e masseteriana são liberadas. Seguem-se zigomaticotomias combinadas a craniotomias frontotemporais. A exposição basal da fossa temporal permite a visualização extradural segura dos forames redondo, oval e espinhoso e do nervo petroso superficial maior com mínima retração cerebral. A artéria carótida intrapetrosa pode ser exposta na região estudada por Glasscock ${ }^{24}$, em 1978, e a asa do osso esfenóide pode ser removida. Os espaços incisurais anterior e médio descritos e o seio cavernoso 
são alcançados. Esse acesso à fossa interpeduncular pode ser ampliado pela remoção do processo clinóide posterior, à semelhança do procedimento demonstrado por Dolenc e cols. ${ }^{17}$ em 1987.

O músculo temporal e o arco zigomático são os principais obstáculos anatômicos para a exposição basal da fossa média. A remoção do arco zigomático expõe a porção inferior do músculo temporal, que pode ser mobilizado inferior ou superiormente, após a secção do processo coronóide da mandíbula, procedimentos que podem levar à disfunção muscular temporal. O deslocamento inferior do músculo é menos deletério à sua irrigação e à sua inervação. Exposições maiores associam-se às técnicas Sekhar e cols..$^{50}$, descritas em 1987, com amplas osteotomias.

Na dissecção proposta em 1992 por Ammirati e cols. ${ }^{4}$, o tendão do músculo temporal ou o processo coronóide não são seccionados, o que preserva o nervo maxilar, e diferem do procedimento descrito por $\mathrm{Al}$ Mefty e cols. ${ }^{2}$, em 1990, porque a inserção tendínea do músculo temporal não é interrompida e o músculo é deslocado inferiormente.

As zigomaticotomias encurtam a distância à incisura tentorial e facilitam, em geral, os acessos sub e infratemporal.

Entre as zigomaticotomias completas situa-se a craniotomia frontotemporoorbitozigomática completa, que se trata da associação da abordagem orbitozigomática a craniotomias de diversas extensões, que propiciam a remoção do retalho ósseo em placa única ou fragmentada.

A abordagem orbitozigomática associa a orbitotomia lateral à remoção do osso zigomático por secção de suas três inserções após seu isolamento subperiostal e descolamento do músculo temporal (figura 6). Tal técnica amplia a exposição inferolateral da órbita, facilitando a cirurgia da fissura esfenoidal superior, das fossas zigomática e pterigomaxilar e do seio maxilar.
As zigomaticotomias já haviam sido propostas com várias finalidades, conforme as citações prévias deste texto. Houve progressiva evolução dos acessos quanto às incisões tegumentares, ao número de osteotomias, à fragmentação do retalho ósseo e à ampliação da craniotomia. A exposição máxima e com retalho ósseo único refere-se à técnica frontotemporoorbitozigomática completa (figura 7).

Considerando que as neoplasias temporoesfenoidais constituem um problema terapêutico, um progressivo desenvolvimento cirúrgico foi necessário para se trabalhar nessa região e nas regiões adjacentes, freqüentemente invadidas. São estas as fossas anterior, média, posterior, pterigopalatina, zigomática e infratemporal, bem como a órbita e as regiões selar e parasselar.

Vias de acesso foram relatadas previamente com craniotomia mais ampla, associada à maior extensão basal orbitomalar, por Joaquim e cols. ${ }^{32}$ em 1987, no Brasil.

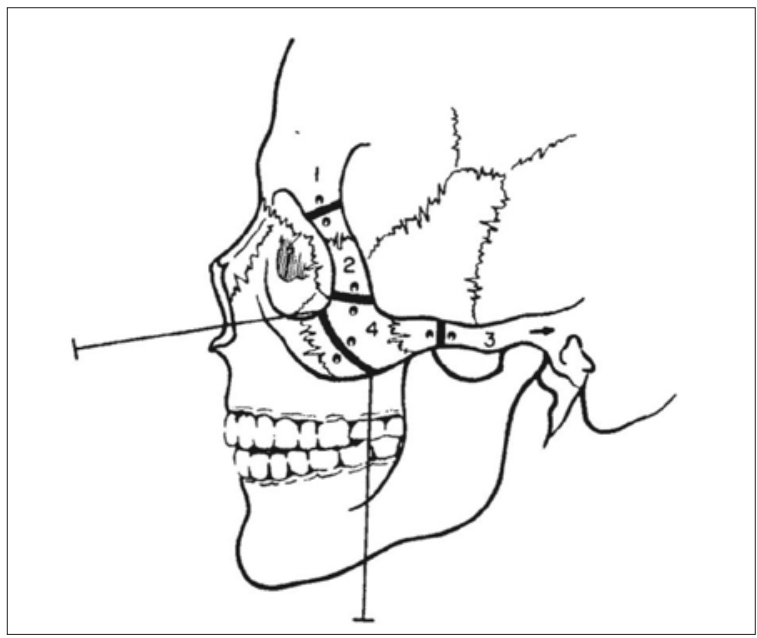

Figura 6 - Osteotomias realizadas na abordagem lateral clássica da órbita (1 e 2) e na via orbitozigomática (1,3 e 4).
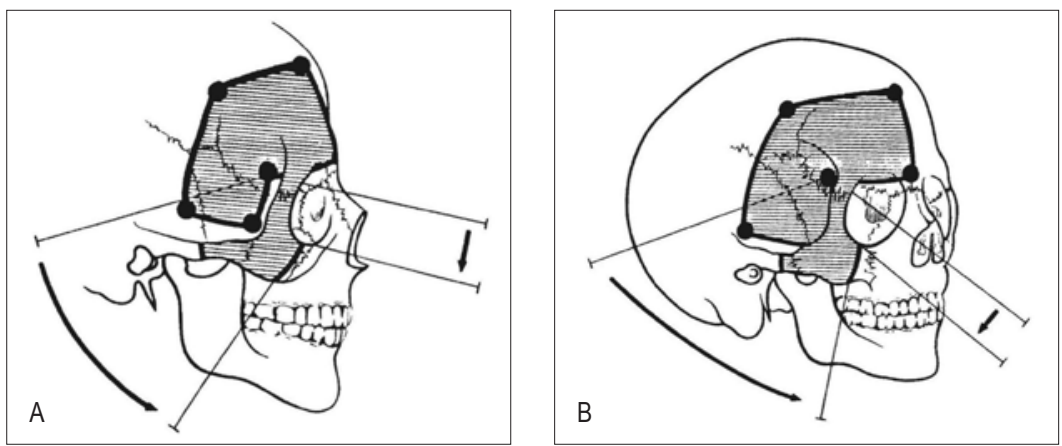

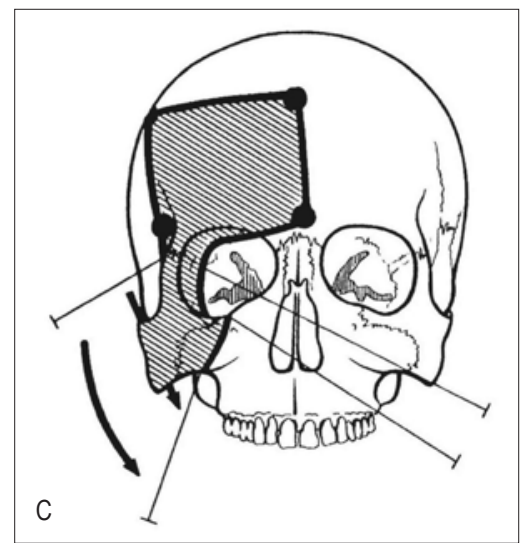

Figura 7A, B e C-Representação esquemática do retalho ósseo frontotemporoorbitozigomático completo. Inferiormente a serra é passada por dentro do arco zigomático para seç̧ão anterior do corpo malar. Na região subtemporal, uma craniectomia expõe a base da fossa média. A asa do esfenóide pode ser removida com broca, incluindo processo clinóide anterior. 
Em 1986, Lesoin e cols. ${ }^{35}$ propuseram a execução de um retalho orbitozigomaticomalar, após a incisão tegumentar de Cairns-Unterberger, citada pelos próprios autores. Realizava-se, em associação, uma craniotomia temporal para a manipulação cirúrgica regional. Ressaltaram-se naquela publicação o controle vascular das lesões pelo acesso às artérias carótida interna e externa e seus ramos, e a possibilidade de manipulação do ápice da pirâmide e da asa do esfenóide. O retalho ósseo possuía, então, dois fragmentos.

Em 1986, Hakuba e cols. ${ }^{26}$ apresentaram uma técnica desenvolvida em 1977 para se ampliar a exposição das lesões parasselares, interpedunculares, esfenoidais, petroclivais, cavernosas e infratemporais. Consistia aquela da realização de uma craniotomia frontotemporoorbitária lateral, que não atingia a linha média, associada a uma zigomaticotomia completa. A diferença básica residia na exérese das porções superior e lateral do teto e do rebordo da órbita. Nessa técnica, denominada de acesso frontotemporoorbitozigomático lateral, a fáscia que cobre a junção temporomandibular e o periósteo externo do zigoma é incisada à frente do tubérculo articular. $\mathrm{O}$ arco zigomático e a rima orbitária são expostos. Segue-se uma craniotomia frontotemporoorbitária lateral que se prolonga para a remoção zigomática à semelhança da técnica em estudo. O fragmento ósseo único permanece aderido ao músculo temporal, formando um retalho pediculado. Esta exposição destinou-se às regiões petroclival superior, esfenoidal, orbitária e à incisura tentorial. Mais tarde, o retalho zigomático foi utilizado em associação à craniotomia nas cirurgias dos tumores do seio cavernoso e da região esfenotemporoorbitária. Foram usados retalhos ósseos múltiplos e a ampliação do campo cirúrgico da fossa craniana anterior, da órbita e da fossa infratemporal foi discutida. Nas mesmas considerações, citou-se a utilização de retalhos ósseos para a reconstrução do assoalho da fossa craniana média, da órbita, do pterion e da região frontomalar, quando estão invadidos e necessitam receber enxertos autólogos regionais de, por exemplo, crista ilíaca. Essa técnica, frontotemporoorbitozigomática lateral, foi considerada fornecedora de melhores campos de visão e de trabalho cirúrgico na região adjacente à fossa craniana média. Nota-se que artérias nutrientes tumorais como as artérias meníngea média e maxilar interna são facilmente isoladas nessa exposição.

Em 1987 a técnica de exposição frontotemporoorbitozigomática completa foi publicada por nós, a partir de estudos realizados com uma junção e uma modificação das técnicas previamente publicadas ${ }^{32}$. Em laboratório, fez-se a craniotomia frontotemporoorbitária completa de Cabrera e cols. ${ }^{8}$, publicada em 1985 no Brasil, e associou-se a remoção, em retalho ósseo único, do osso zigomático. Várias osteotomias complementares foram experimentadas nas dissecções. A partir da craniotomia, continua-se a secção óssea inferiormente, através da parede lateral da órbita e da junção zigomático-maxilar. Seccionou-se, em seguida, a inserção posterior do osso zigomático. Tal craniotomia atingia a linha média incluindo todo o teto da órbita ${ }^{32}$.

$\mathrm{O}$ acesso transzigomático despontou-se como técnica para exposição da região do seio cavernoso, em que se associam, à craniotomia pterional, a zigomaticotomia e a remoção da parte ântero-externa do rebordo orbitário. Extensão para a parte superior do clivus, tentório ou ápice da pirâmide pode ser obtida com associação de acesso transpetroso.

Pode-se remover todo o osso zigomático com sua inserção masseteriana, utilizando o acesso zigomaticotemporal, permitindo uma abordagem mais anterior da cisterna interpeduncular ao longo da superfície inferomedial do lobo temporal, com pouca retração cerebral. Inicialmente, nessa abordagem, os autores utilizaram uma incisão em ferradura com um prolongamento pré-auricular e outro infra-orbitário para se abordar a região da junção temporomandibular. Em seguida, passou-se à incisão quase bi-coronária, prolongada à linha temporal superior contralateral. Disseca-se o osso zigomático por via interfascial, antes da osteotomia e da craniotomia.

Desde as primeiras descrições, muitos tipos diferentes de osteotomias zigomáticas e orbitozigomáticas foram utilizados. As osteotomias orbitárias poderiam ser uni ou bilaterais, em combinação com a osteotomia frontoetmoidal, para reduzir a retração frontal. As osteotomias zigomáticas otimizariam a exposição do setor medial da fossa craniana média, do hiato tentorial e da região clival superior, além de permitirem a exposição parcial das fossas infratemporal e pterigomaxilar, até a parede lateral do seio esfenoidal. A osteotomia zigomática posterior era sempre realizada em frente à articulação temporomandibular, porém pode ser realizada posteriormente a esta, após remoção da articulação. A ressecção do côndilo mandibular seria associada quando se pretendia expor todo o segmento petroso da artéria carótida interna ou para o acesso a determinadas lesões clivais.

Pode-se dividir o retalho ósseo em dois fragmentos, um frontotemporal e outro orbitozigomático, o que proporciona a realização da orbitectomia total em bloco com essa técnica cirúrgica, além da microcirurgia do conteúdo orbitário. Segundo Joaquim e cols. ${ }^{32}$, com o acesso frontotemporoorbitozigomático, as esfenoidectomias, as orbitotomias e os acessos infratemporais poderiam ser realizados e submetidos à reconstrução de maneira satisfatória.

Em 1991, Uttley e cols. ${ }^{61}$ demonstraram sua experiência em 55 operações de lesões situadas na parte medial da asa do esfenóide e na cisterna interpeduncular, 
num período de três anos, utilizando-se da mobilização do osso zigomático com um retalho ósseo adicional, em separado do retalho de uma craniotomia temporal que foi realizada. Tratava-se de uma expansão zigomática anterior da técnica apresentada por Pitelli e cols. ${ }^{37} \mathrm{em}$ 1986. Tais autores consideraram as dificuldades de exposição e a necessidade de retração cerebral associadas às operações de lesões da base do crânio por via frontotemporal convencional, demonstradas nos itens específicos deste texto.

O retalho ósseo em bloco único, frontotemporoorbitário lateral, pode ser utilizado em associação ao acesso pré-temporal ou temporopolar descrito por $\mathrm{Sano}^{43} \mathrm{em}$ 1980. Após a craniotomia, as veias em ponte do pólo temporal e de sua base são coaguladas, a cisterna silviana, aberta e a ponta do lobo temporal é retraída posteriormente. Aneurismas da bifurcação da artéria basilar foram abordados, aparentemente com melhor exposição do que a obtida nos acessos pterionais e nos acessos subtemporais. Nesses aneurismas deve ser estudada sua distância até o processo clinóide posterior, considerando-se que as deficiências neurológicas pós-operatórias são menos comuns, quando o colo encontra-se acima da linha interclinóidea e a artéria carótida interna é longa. $\mathrm{O}$ deslocamento posterior da artéria basilar, além de $10 \mathrm{~mm}$ do processo clinóide posterior, associa-se ao aumento da morbidade cirúrgica, quando se utiliza o acesso pterional. Assim, aneurismas muito altos associados a artérias carótidas internas curtas implicam maior dificuldade cirúrgica. Tais achados implicam a execução de uma via de acesso que permita adequada exposição. Outras variações da anatomia vascular, relacionadas à artéria comunicante posterior e suas perfurantes, à artéria cerebral posterior e à artéria cerebral anterior interferem também nos procedimentos. Para superar tais dificuldades, Ikeda e cols. ${ }^{30}$, em 1991, consideraram que as osteotomias adicionais aumentaram o espaço de exposição cirúrgica. Tais osteotomias incluíram o teto da órbita, o processo clinóide posterior, o arco zigomático e a asa do osso esfenóide, permitindo uma visualização ínfero-superior da lesão e minimizando a retração cerebral.

É interessante notar que as abordagens supraorbitária e orbitocraniana, assim como suas variações, permitem acessos mais anteriores, enquanto os acessos zigomáticos são mais inferiores e laterais. Os acessos orbitozigomáticos são multidirecionais em virtude de sua amplitude externa. Ikeda e cols. ${ }^{30}$, em 1991, consideraram ser a abordagem zigomática preferencial para o acesso à cisterna interpeduncular, pois o acesso orbitozigomático infratemporal seria muito extenso para se operar os aneurismas dessa região. O acesso orbitozigomático temporopolar utilizado pelos autores seria o escolhido para aneurismas altos da bifurcação da artéria basilar associados à artéria carótida interna curta em virtude da ampla exposição, que permitiria um acesso multidirecional, associado à menor retração cerebral, fato discutível quando se considera a retração posterior do pólo temporal. Ikeda e cols. ${ }^{30}$ recomendaram seu acesso para aneurismas situados além de $20 \mathrm{~mm}$ acima da linha interclinóidea.

Em 1992, Delashaw e cols. ${ }^{13}$ propuseram a modificação técnica que permite maior exposição por incluir na craniotomia o lado oposto do osso frontal. À craniotomia frontotemporoorbitozigomática completa associou-se a osteotomia frontal contralateral. A possibilidade da ampliação do ângulo de exposição das lesões da fossa anterior, por ser permitida a visualização pelo lado oposto, melhoraria as condições de dissecção. Nessa técnica, outros autores também propuseram a remoção osteoplástica da parede anterior do seio frontal, pois permite uma reconstrução estética adequada. Além da sinusectomia frontal, os autores propuseram osteotomias adicionais, quando necessário, do teto da órbita, da asa do esfenóide e do processo clinóide anterior.

Sindou e cols. ${ }^{53}$, em 1990, consideraram que lesões basais profundas requerem, na sua operação, retração cerebral que pode causar infartos e seqüelas neurológicas, atentando para os fatos de que a remoção do rebordo orbitário superolateral, à semelhança das considerações de $\mathrm{Al} \mathrm{Mefty}{ }^{1}$ em 1987, e à remoção do arco zigomático, ou de ambos, associados ao acesso pterional, promovem "ganho de espaço" à cirurgia. Sindou realizou a craniotomia pterional e em seguida a remoção do bloco orbitozigomático. Após dois estudos anatômicos realizados por Sindou e cols. ${ }^{53}$, em 1990, os autores mediram os ângulos do campo de visão para um alvo intracraniano com e sem a remoção complementar do retalho orbitozigomático. Considerando o acesso subfrontopterional com o alvo no complexo optocarotídeo, obteve-se o ângulo adicional de $8,3^{\circ}$ $(74,1 \%)$, em plano vertical não especificado ${ }^{53}$. No acesso frontopteriotemporal, com o alvo na bifurcação da artéria basilar, o ângulo de exposição aumentou de $22,5^{\circ}$ para $32,9^{\circ}(46,2 \%)$, no plano transversal, no acesso pré-temporal ${ }^{53}$. Os conceitos de planos, eixos e ângulos não foram especificados ou denominados. No acesso subtemporal, com alvo na artéria cerebral posterior, o ângulo aumentou de $8^{\circ}$ para $14,9^{\circ}(86,2 \%)$, em plano vertical não identificado e considerando-se, provavelmente, a presença e a ausência do músculo temporal ${ }^{53}$. Os autores consideram que a osteotomia orbitária é preferencial para lesões optoquiasmáticas ou uncoamigdaloipocampais; que a remoção do arco zigomático é indicada para se tratar lesões do assoalho da fossa média; e que a remoção orbitozigomática combinada destina-se a lesões cavernosas e interpedunculares. $\mathrm{O}$ acesso pré-temporal seria facilitado (figura 8). 


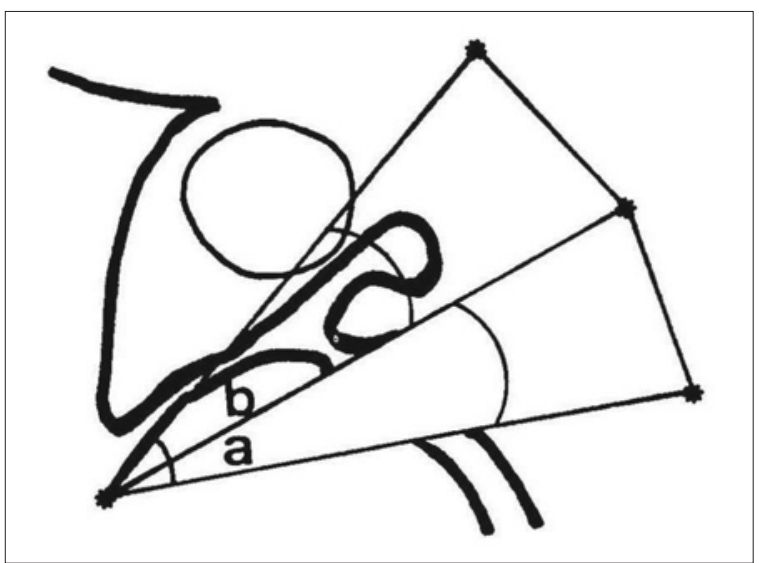

Figura 8 - A remoção do rebordo lateral da órbita amplia a exposição angular no plano semi-axial e facilita o acesso pré-temporal.

Atentou-se para a importância da retração cerebral na cirurgia da base do crânio. $\mathrm{O}$ acesso pterional-orbitozigomático osteoplástico foi realizado por meio de três retalhos ósseos. Delfini ${ }^{14}$, no mesmo ano, considerou a execução do retalho orbitozigomático em bloco único, associado a osteotomias adicionais que incluíram a clinoidectomia, e descreveram a possibilidade de buscar no campo um acesso realmente tangencial aos planos basais das fossas anterior e média, desconsiderando a criação de espaço através do viscerocrânio. Foi considerado o acesso combinado à fossa infratemporal. Essa técnica foi utilizada em neoplasias malignas invasivas e em meningiomas em busca de ressecções mais radicais.

Sengupta $^{52}$, em 1994, não considerou a osteotomia zigomática ampla absolutamente necessária para facilitar o acesso à cisterna interpeduncular, provavelmente por preferir o trabalho pelo neurocrânio, utilizando-se das técnicas convencionais para minimizar a retração cerebral.

A expansão orbitozigomática da craniotomia orbitocranial associada ao acesso temporopolar foi revista para aneurismas da bifurcação da artéria basilar e da emergência da artéria cerebelar superior. Sugeriu-se que o acesso pterional convencional apresentava visualização na direção superior limitada pelas estruturas ósseas ao redor do espaço de trabalho. A ampliação da via de acesso foi principalmente proposta para os aneurismas altos associados à artéria carótida interna supraclinóidea curta. Tal expansão da craniotomia foi considerada como minimizadora da retração cerebral e fornecedora de um acesso cirúrgico multidirecional.

Buscando ainda maior exposição basal por meio de grandes osteotomias, conjugaram-se, à técnica em estudo, acessos que incluem a fossa infratemporal,as petrossectomias, as maxilotomias e as osteotomias occipitais.
Um aumento adicional da exposição com mínima retração cerebral seria obtido com a secção do nervo mandibular para se alcançar a linha média. A ressecção do côndilo mandibular também foi usada. As zigomaticotomias são uma constante nesses acessos, de uso cada vez mais estabelecido e rotineiro.

As cirurgias dos meningiomas esfenoidais e cavernosos motivaram a execução de técnicas cirúrgicas agressivas para aumentar o radicalismo da ressecção dos tumores apresentados. A ampla remoção óssea das fossas anterior e média foi preconizada por Pompili e cols. ${ }^{43}$ em 1982. Na série de Mc Dermott e cols. ${ }^{37}$ em 1990, as asas esfenoidais estavam invadidas por neoplasia em todos os casos, a órbita em $75 \%$ e a fossa infratemporal em $25 \%$ dos doentes.

Bonnal e cols. ${ }^{6}$, em 1980, relataram as limitações mais importantes à ressecção completa dos meningiomas invasivos pelo acesso frontotemporal: invasão do seio cavernoso, da dura-máter selar, do seio esfenoidal, do ânulo de Zinn e da fossa pteriogomaxilar, estruturas que poderiam ser abordadas por vias de acesso mais extensas.

As condições para a recorrência dos meningiomas intracranianos foram recentemente consideradas, revelando-se importante o radicalismo das ressecções. Particularmente os meningiomas esfenoidais e em placa sobre a asa do osso esfenóide, invadindo a fossa média, foram associados a complicações cirúrgicas e à recorrência. A evolução das técnicas de abordagem parece ter ampliado os critérios de operabilidade e ressecabilidade desses tumores.

Meningiomas do seio cavernoso, primários ou secundários, têm sido ressecados, segundo revelam as publicações, de 1986, de Sekhar e cols. ${ }^{48}$. Os autores mobilizam o zigoma e a margem da órbita. Nesse estudo, meningiomas cavernosos foram removidos sem prejuízo significativo dos doentes, em relação à presença da lesão e à opção de não tratamento. Tumores residuais menores poderiam ser submetidos a técnicas de radioterapia localizada.

Lesões vasculares das mesmas regiões podem ser abordadas utilizando-se as mesmas técnicas. Considerando os acessos através da base do crânio para aneurismas cerebrais de maior complexidade cirúrgica, utilizam-se as técnicas orbitocranial e orbitozigomática para aneurismas da circulação anterior, e as técnicas de abordagem petrosa ou transcondilares occipitais laterais, para aneurismas da circulação posterior. Recentemente, considerou-se a possibilidade de que, mesmo sendo os aneurismas lesões predominantemente cisternais, haveria benefícios de sua abordagem através da base do crânio.

Origitano e cols. ${ }^{39}$, em 1993, enfatizaram a necessidade da ampliação da exposição e a presença dos efeitos deletérios da retração cerebral, principalmente sobre o encéfalo em sofrimento após a hemorragia menín- 
gea, além de considerarem a importância do controle vascular proximal, eventualmente através da base do crânio, com ou sem secção tentorial. As vantagens do acesso aos aneurismas complexos através da base do crânio são a possibilidade de controle proximal e distal dos vasos, o oferecimento de múltiplos ângulos visuais para a dissecção, a minimização da retração cerebral, o encurtamento da distância entre o cirurgião e seu objetivo, a ampliação do campo cirúrgico, os bons resultados estéticos e a eventual possibilidade do "ataque" direto à cisterna que contém a lesão. A manipulação da pirâmide petrosa e do seio cavernoso é uma possibilidade adicionais. Ressalta-se aqui o axioma de Origitano e cols. ${ }^{39}$, estabelecido em 1993: "drill bone, save brain".

As operações descritas de mobilização do zigoma e da órbita, associadas às craniotomias, chegam a reduzir a distância da lesão à superfície em até $3 \mathrm{~cm}$ e permitem considerar um acesso multidirecional às lesões. Permite-se também a exposição associada da fossa infratemporal.

A craniotomia frontotemporoorbitozigomática foi também utilizada para tumores da fossa infratemporal que invadiam a fossa craniana média e para neurinomas trigeminais gigantes.

\section{Osteotomias complementares}

As osteotomias complementares são procedimentos realizados após a execução da craniotomia e que têm por objetivo permitir a manipulação mais ampla e segura, por meio da microcirurgia, das estruturas anatômicas relacionadas à base do crânio. São utilizadas em diferentes combinações, de acordo com as necessidades específicas de cada caso. A seguir serão comentados os procedimentos mais sistematizados como osteotomias complementares e suas variações, e ao final será comentada a reconstrução da base do crânio.

\section{Esfenoidectomias}

A remoção não osteoplástica da asa do esfenóide é um procedimento convencional para a exposição basal pterional. Há diferentes extensões de ressecções descritas, desde osteotomias laterais até exposições amplas da fissura orbitária superior, da órbita e do canal óptico, incluindo ou não o processo clinóide anterior.

\section{Clinoidectomias}

Os processos clinóides são pontos parasselares de inserção dural, de onde partem várias dobras paquime- níngeas que constituem compartimentos continentes ou pontos de apoio e inserção de estruturas neurovasculares. As clinoidectomias anteriores relacionam-se a procedimentos carotídeos e esfenoidais e as posteriores, a procedimentos basilares e clivais (figura 9).

A

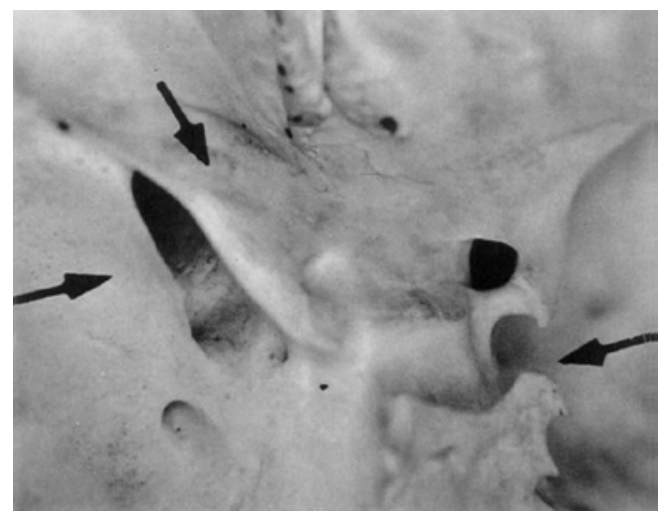

B

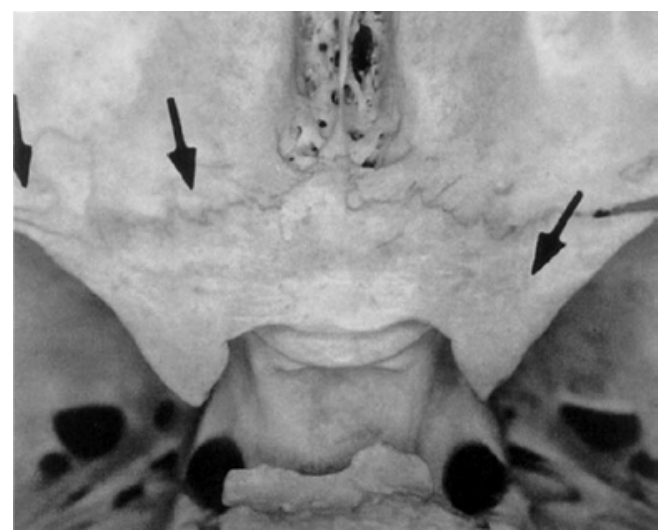

Figura 9 A e B - Topografia óssea dos processos clinóides anterior e posterior.

O processo clinóide anterior é um ponto de reparo importante na consideração do compartimento anterior do seio cavernoso. Pode estar fundido ao processo clinóide médio formando o forame carótido-clinóideo, ou aderir-se a uma ponte óssea interclinóidea. É o ponto de inserção das pregas interclinóidea e petroclinóidea anterior. Sua remoção expõe o segmento clinóideo da artéria carótida interna, parte do nervo oculomotor e a membrana carótido-oculomotora.

A asa menor do osso esfenóide cursa medialmente e divide-se em duas raízes. A raiz superior, plana, forma o teto do canal óptico e continua-se como plano esfenoidal. A inferior, ou suporte óptico, forma as paredes lateral e ventral do canal óptico e conecta a asa menor com o corpo do osso esfenóide.

O processo clinóide anterior é a mais medial e posterior continuação da asa menor. O suporte óptico continuase medialmente com a crista optocarotídea. O processo clinóide anterior é normalmente composto de uma fina 
concha de osso cortical e do osso trabecular interno. Ocasionalmente contém celas aéreas que se comunicam com o seio esfenoidal através do suporte óptico.

O forame carótido-clinóideo forma-se entre os processos clinóides anterior e médio e separa os segmentos clinóideo e intradural da artéria carótida interna. $\mathrm{O}$ anel dural distal apoia-se neste forame, cuja fusão óssea pode ser incompleta. Se o forame estiver ausente, é substituído pelo ligamento carótido-clinóideo.

O processo clinóide anterior serve como inserção do tentório através da prega petroclinóidea anterior, que separa as paredes superior e lateral do seio cavernoso e, com as pregas posterior e a interclinóidea, forma o triângulo do nervo oculomotor, que constitui os dois terços posteriores do teto do seio cavernoso, já que o terço anterior é coberto pelo processo clinóide anterior (figura 10).

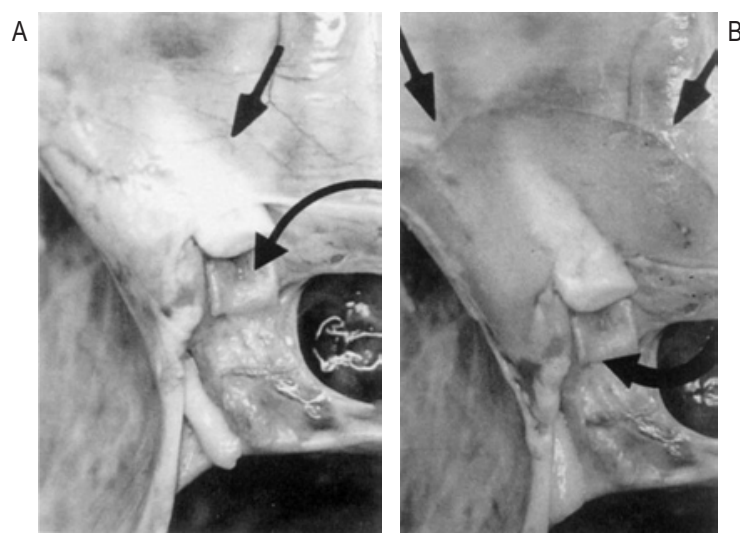

C

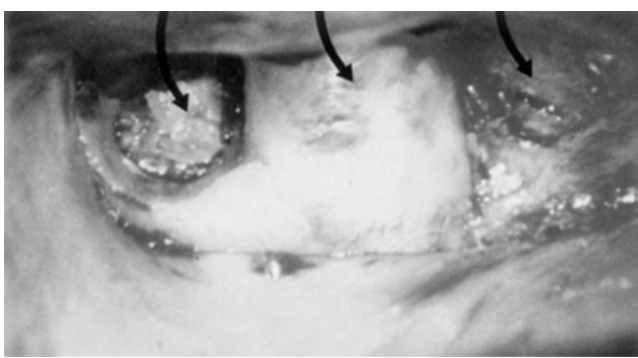

Figura 10A, B e C-Clinoidectomia anterior extradural. Nota-se nas figuras superiores a exposição do processo clinóide anterior para verificação das relações anatômicas. Na figura inferior, por via extradural, as setas indicam, da esquerda para a direita, o espaço clinóideo, a bainha do nervo óptico e a mucosa do seio esfenoidal.

A clinoidectomia anterior extradural inclui a ressecção óssea adjacente, ou seja, teto da órbita, canal óptico e asa do osso esfenóide. A retirada do teto do canal óptico permite a mobilização do nervo. A dificuldade na mobilização do processo clinóide anterior pode dever-se à sua conexão com os processos clinóides posterior ou médio.
A clinoidectomia anterior intradural tem as vantagens de oferecer a visualização direta das relações anatômicas, para a proteção carotídea e óptica, e o controle distal da artéria carótida interna. A desvantagem reside na exposição dessas estruturas neurovasculares a potencial lesão pela broca.

A origem da artéria oftálmica define com proximidade a entrada da artéria carótida através da dura-máter. A relação do segmento clinóideo com o supraclinóideo é notada após a remoção do processo clinóide anterior e abertura dural de modo a se expor o anel dural e o ainda indefinido anel extradural composto pela membrana carótido-oculomotora que separa os canais do seio cavernoso do espaço clinóideo.

A remoção convencional intradural do processo clinóide anterior realizada no tratamento cirúrgico dos aneurismas carótido-oftálmicos foi exposta em muitas publicações, e várias extensões de osteotomias foram realizadas, mas foi após a execução da orbitotomia apical e da clinoidectomia anterior realizada por Dolenc ${ }^{16}$, em 1985, por via extradural que essas remoções ósseas se sistematizaram. Nessa técnica, expõem-se o canal e o nervo ópticos - cuja bainha é aberta para permitir sua mobilização -, a fissura orbitária superior e o segmento clinóideo da carótida interna. Esse autor, adicionalmente, apresentou nove triângulos que delimitam espaços anatômicos relacionados ao seio cavernoso.

A manipulação cirúrgica de neoplasias que invadem o compartimento anterior do seio cavernoso, órbita e fissura orbitária pode requerer a clinoidectomia anterior. Nessa situação, a anatomia da fissura orbitária superior deve ser conhecida. A grande parte dos autores realiza a clinoidectomia anterior após a esfenoidectomia para operar neoplasias do seio cavernoso.

A clinoidectomia posterior foi proposta por Dolenc e cols. ${ }^{17}$ para o acesso a determinados aneurismas da bifurcação da basilar. O espaço petroclival superior, que tem como centro a cisterna interpeduncular, limitada pelos dois folhetos da membrana da Lilliequist, contém o seio cavernoso e os pedúnculos cerebrais, é dividido em compartimentos supra e infratentorial e tem no processo clinóide posterior um ponto de referência do seu limite anterior, pois nele se insere o folheto anterior da membrana aracnóidea citada.

\section{Remoção da crista-galli}

A crista-galli pode ser removida por via extradural para se permitir o isolamento dos manguitos durais que envolvem os nervos olfatórios. Tal manobra permite a manipulação parcial da fossa anterior do crânio e a secção unilateral do nervo e bainha olfatórios para determinadas cirurgias, preservando a olfação contralateral (figura 11). 


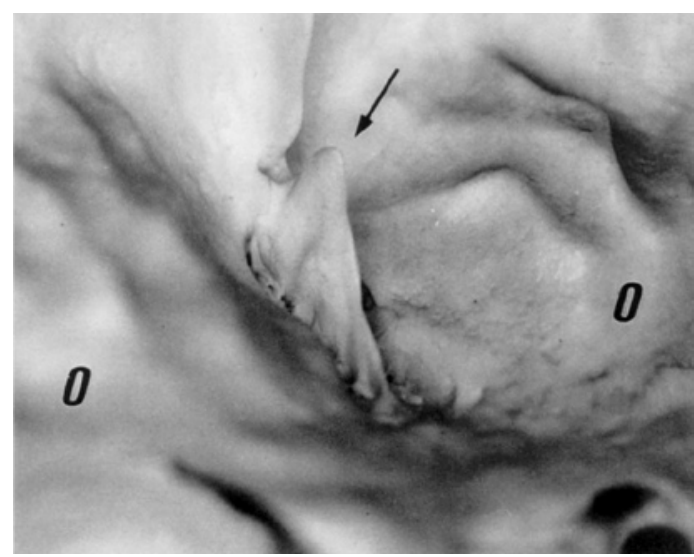

Figura 11 - Topografia da crista-galli entre as órbitas (O) e atrás da crista frontal interna.

\section{Maxilectomias}

As maxilectomias radicais foram usadas para neoplasias invasivas da região, criando defeitos faciais que exigiram técnicas de reconstrução complexas. Entretanto, como acesso à porção central da base do crânio, foi proposta uma maxilectomia osteoplástica que aumentava também o acesso às fossas infratemporal e pterigopalatina. Uma maxilectomia foi a via de acesso para aneurismas da artéria basilar e foi associada ao degloving e a técnicas de exérese de tumores da linha média, até a zigomaticotomia.

Podem-se alcançar massas extradurais em abordagens centrofaciais, trabalhando-se através da cavidade nasal, e em abordagens combinadas transantral-palatalpterigóide-malares, que associam à abordagem centrofacial a maxilectomia sinusal não osteoplástica para $o$ acesso à porção anterior da fossa infratemporal.

A utilização de retalho maxilar pediculado, ou nasomaxilar, combinado ou não a outras osteotomias, para o acesso à base craniana anterior, proporciona boa possibilidade de reconstrução.

\section{Mandibulectomias}

A osteotomia mandibular pode envolver o processo coronóide, o tubérculo articular, ou todo o seu segmento ascendente, contribuindo para a ampliação do acesso às lesões da fossa infratemporal. Estas podem ser tumores subtemporais, maxilares ou intra-orais. Usualmente, associa-se uma parotidectomia e a dissecção cuidadosa do nervo facial, e removem-se, em conjunto, o arco zigomático, parte do osso maxilar e parte da parede da órbita. Podem ser necessárias a desarticulação ao nível da cavidade glenóide e a dissecção cervical ampla.

$\mathrm{O}$ acesso transmandibular pode ser combinado à técnica transzigomática para a abordagem da fossa pterigopa- latina. Essa associação foi utilizada para a abordagem da região compreendida entre o osso maxilar anteriormente, o processo pterigóide posteriormente e os ossos palatino e esfenóide superiormente. Essa região comunica-se com a cavidade nasal através do forame esfenopalatino, com a órbita através da fissura orbitária inferior, com a fossa craniana média através do canal pterigóide e do forame redondo, e com a cavidade oral através do canal palatino. Tal mandibulectomia é uma alternativa ao acesso anterior quando associada à maxilectomia.

\section{Petrossectomias laterais parciais e completas}

O osso temporal é o maior componente da região petroclival, insere o tentório e separa as fossas posterior e média. É dividido em partes timpânica, escamosa, mastóidea e petrosa. A parte timpânica forma as paredes anterior e inferior. O canal carotídeo e o forame jugular situam-se medialmente ao osso timpânico. Em relação à parte petrosa, o osso labiríntico consiste das partes vestibular, coclear e dos canais semicirculares. $\mathrm{O}$ canal semicircular superior determina a eminência arqueada, e o meato auditivo interno é encontrado anteriormente à eminência arqueada em um ângulo de $60^{\circ}$ a partir do canal semicircular superior. Esse canal superior pode ser lesado na abordagem ao meato acústico interno a partir da fossa média. A face superior do osso petroso forma a parte posterior do assoalho da fossa média. Neste, o tegmen timpani, teto da cavidade timpânica, situa-se ânterolateral à eminência arqueada. O nervo grande petroso é identificado medialmente à eminência arqueada à medida que este deixa o gânglio geniculado. Corre sob a duramáter, na goteira esfenopetrosa, ântero-lateral e superiormente ao segmento petroso da artéria carótida interna, e sua manipulação pode gerar uma paralisia facial. A cóclea está abaixo do assoalho da fossa média, medial ao gânglio geniculado, e próxima ao joelho do segmento petroso da artéria carótida interna. Esta, dentro do canal carotídeo, é envolvida por densa rede conjuntiva e relaciona-se, no segmento horizontal, anteriormente, com a tuba de Eustáquio e o músculo tensor do tímpano. $\mathrm{O}$ forame espinhoso, ponto de entrada da artéria meníngea média, está ântero-lateral em relação ao gânglio geniculado. O forame jugular está localizado no segmento inferior da fissura petrooccipital. O meato acústico interno está à meia distância entre a base e o ápice da pirâmide, na superfície petrosa posterior.

Os tumores que se estendem à região petroclival são o objetivo de um desenvolvimento técnico de acessos cirúrgicos que vêm ocorrendo nos últimos anos, visando aumentar a exposição das estruturas anatômicas adjacentes, geralmente modificadas na sua posição. Para exposição de toda a região clival, pode-se combinar as vias em questão, com extensa remoção óssea supra e 
infratentorial. Incluiu-se neste item a cirurgia da fossa craniana posterior trabalhando-se através da fossa média ou da fossa infratemporal, este combinando abordagens através das fossas média e posterior, assim como o descrito por Samii e cols. ${ }^{45}$, em 1988, combinando o acesso pré-sigmóideo.

Considerando que, intuitivamente, o campo operatório nessa situação é predominantemente cônico sob o ponto de vista tridimensional, nota-se que existe uma crescente tendência de diminuir a distância da superfície ao alvo cirúrgico e de ampliar o campo de trabalho do cirurgião, minimizando a retração cerebral e permitindo maior conforto e segurança na manipulação profunda.

A anatomia topográfica dos acessos laterais à região petroclival foi estudada por Tedeschi e cols. ${ }^{59} \mathrm{em} 1994$ e, neste trabalho, os autores demonstraram a importância de reparos ósseos anatômicos para se calcular distâncias de acesso cirúrgico. As regiões petroclival superior, inferior e posterior foram estudadas em termos de distâncias interforaminais até a superfície do crânio. A topografia óssea foi utilizada como base para a localização das estruturas neurovasculares.

A técnica translabiríntica promove acesso a todo o nervo facial, ao conteúdo do meato auditivo interno, à borda inferior do nervo trigêmeo, à face lateral da ponte, e não permite exposição adequada da região inferior ao bulbo jugular, superior ao nervo trigêmeo e anterior ao meato acústico interno.

A técnica transcoclear facilita a translocação do nervo facial e permite melhor visualização da região anterior ao meato auditivo. Sua combinação com o acesso infratemporal constitui a técnica pós-auricular transtemporal, uma alternativa à técnica pré-auricular infratemporal, usada quando a neoplasia acomete o recesso facial, a mastóide, a fossa infratemporal, a área hipotimpânica e o bulbo jugular. Pode-se comentar que a abordagem infratemporal fornece ampla exposição das estruturas da linha média, mas necessita reposicionamento anterior do nervo facial, subluxação ou ressecção do côndilo mandibular, petrossectomia subtotal e obliteração do ouvido médio, com perda da audição.

A técnica retrolabiríntica transsigmóidea foi utilizada para o acesso a lesões vasculares vertebrobasilares.

Técnica adicional para minimizar a retração cerebral na abordagem subtemporal foi apresentada por Sindou e cols. ${ }^{54} \mathrm{em} 1991$. Notando-se a pequena dimensão do espaço subaracnóideo subtemporal e a presença da veia de Labbé e das veias tributárias aos seios tentoriais, considerou-se que a remoção extradural do teto do meato auditivo e de parte da pirâmide, com cuidado para não se abrir o tegmen timpani, facilitaria a exposição. Nesta publicação os autores descreveram um espaço piramidal de base externa ganho pela remoção do teto do meato auditivo externo que fornece um comparti- mento adicional para melhores visão e manipulação dos instrumentos microcirúrgicos. Há facilitação do acesso à artéria cerebral posterior. Publicação mais recente ${ }^{35}$ exemplifica, através de um desenho, o ângulo obtido no plano vertical que passa sobre o meato acústico interno, cujo valor é de $27^{\circ}$, comparando-o com o ângulo inicial obtido apenas com a retração cerebral, de $17^{\circ}$.

Gleeson $^{25}$ em 1994 comparou os ângulos de exposição em plano transversal, tendo como alvo aproximado o ápice da pirâmide, obtidos pelas vias retrolabiríntica, translabiríntica e pelo acesso tipo B de Fisch, através da associação à exposição da fossa infratemporal, que fornece maior campo operatório.

No acesso transpetroso transcoclear extradural ao clivus, a cóclea é removida e o nervo facial, transposto. $\mathrm{O}$ acesso transpetroso transtentorial conjuga-se à necessidade da remoção do ducto endolinfático, do canal semicircular horizontal, da abertura da parte posterior do antrum sem manipulação dos ossículos e da abertura parcial do teto do meato auditivo interno, além da mastoidectomia. No acesso subtemporal préauricular infratemporal, alcança-se a face anterior da ponte e nos acessos retro e préauriculares transpetrosos transtentoriais associados à zigomaticotomia.

\section{Petrossectomias parciais apicais e paracarotídeas}

A anatomia topográfica microcirúrgica da exposição da porção petrosa da artéria carótida interna foi bastante estudada. A anatomia do ápice petroso está cirurgicamente relacionada nos trabalhos de Tedeschi e cols. ${ }^{59}$, publicado em 1994, e de Kawase e cols. ${ }^{33}$, publicado em 1991, assim como a associação com a exposição do segmento superior da carótida cervical.

As relações do canal carotídeo são importantes nos acessos intracranianos temporais, transpetrosos translabirínticos, transcoclear e ao seio cavernoso. Cerca de um centímetro de comprimento arterial pode ser exposto lateralmente ao nervo trigêmeo. O conteúdo complementar do canal carotídeo inclui, entre outros menos freqüentes, os ramos arteriais intrapetrosos caroticotimpânico e vidiano, o plexo venoso periarterial e o plexo neural periarterial. $\mathrm{O}$ nervo grande petroso corre paralelamente ao segmento exposto. A delimitação anatômica do triângulo descrito permite a dissecção adequada. São pontos de referência importantes: o forame espinhoso, a eminência arqueada e o nervo petroso superficial maior, que é seccionado antes da remoção do teto do canal carotídeo. O gânglio de Gasser, dentro do cavo de Meckel, recebe sua raiz posterior que faz uma impressão no ápice da pirâmide, sobre a parte medial da carótida petrosa, que pode ser exposta removendo-se o osso lateral ao gânglio. 
Assim, se se deseja ter acesso à carótida interna na base do crânio, a maioria dos acessos laterais é útil, entretanto compromete a audição. Uma abordagem superior permite exposição do segmento intrapetroso da artéria. A abordagem ântero-externa discutida por Lesoin e cols. ${ }^{35}$ é uma extensão desses acessos que expõem toda a carótida petrosa e cavernosa sem sacrifício da audição. Neste acesso realiza-se uma craniotomia frontotemporoorbitozigomática lateral, chamada por aqueles autores de retalho orbitozigomaticomalar, expondo-se as fossas temporal e pterigomaxilar. A superfície petrosa ântero-superior é exposta por via extradural. Os dois nervos petrosos, emergindo do hiato de Falópio e do hiato acessório, são expostos e seccionados para impedir a tração que gera paralisia facial periférica. A artéria meníngea média é coagulada e seccionada ao nível do forame espinhoso. O descolamento dural segue até o cavo de Meckel e o nervo mandibular, no forame oval. A face ântero-lateral do osso petroso é exposta entre a eminência arqueada e o forame oval, e este espaço conduzirá ao seio petroso superior, na borda superior da pirâmide. Para se localizar o segmento horizontal da carótida petrosa, utiliza-se como pontos de reparo o nervo petroso superficial maior, a artéria meníngea média e o forame oval.

Se se deseja expor toda a artéria, inclusive extracraniana, pode ser necessário luxar a mandíbula, seccionar o côndilo ou ressecar a cavidade glenóide.

A dissecção da porção vertical vem da continuidade da dissecção do segmento horizontal, retrogradamente. As relações com a cóclea, o gânglio geniculado e o ouvido médio são conhecidas e a tentativa de preservação da audição implica abrir-se apenas a parede anterior do canal carotídeo. O plexo venoso periarterial e os ramos intrapetrosos da artéria carótida são coagulados e seccionados para a liberação completa do vaso.

No acesso subtemporal transpetroso anterior, realiza-se uma dissecção extradural após uma craniotomia temporal. Expõem-se o forame espinhoso, a eminência arqueada e o nervo petroso superficial maior. O limite lateral da exposição cirúrgica é a parede anterior do canal auditivo interno. O limite anterior é dado pela artéria carótida petrosa. $\mathrm{O}$ ápice da pirâmide é removido medialmente até a exposição do seio petroso inferior na borda lateral do clivus. Trabalha-se entre os nervos trigêmio e facial. Segundo Tedeschi e cols. ${ }^{59} \mathrm{e}$ Kawase e cols. ${ }^{33}$, o ângulo de visão através da área da petrossectomia pode ser aumentado se se realizar uma craniotomia frontotemporozigomática. A combinação da técnica subtemporal com a pré-auricular infratemporal expõe a base ântero-lateral do crânio através da parte anterior da pirâmide e difere de outras técnicas em relação à manipulação do nervo facial e do aparelho condutivo da audição.
A técnica exata da petrossectomia apical consiste na exposição extradural da dura-máter própria do nervo mandibular, do nervo petroso superficial maior e do forame espinhoso, seguida da secção da artéria meníngea média e do nervo petroso e da remoção do teto do canal carotídeo. $\mathrm{O}$ ápice petroso é removido posteriormente à artéria carótida e inferiormente à dura-máter própria do nervo trigêmeo. As estruturas do ouvido interno, ou seja, a cóclea, o nervo vestibulococlear, o gânglio geniculado e os canais semicirculares, estarão lateralmente situadas em relação à linha imaginária que sai do forame espinhoso e corre paralela à linha média. A observação da sincondrose occipitoesfenoidal indica que foi alcançada a parte lateral do clivus, que pode ser removida até sua metade, revelando a face ânteromedial da dura-máter da fossa posterior e o seio petroso inferior. A abertura dural expõe as artérias basilar e cerebelar ântero-inferior, o nervo abducente e a face anterior da ponte.

É possível abordar a porção superior do ângulo pontocerebelar através de uma craniotomia na fossa média e da retirada do osso medial à cóclea e ao segmento petroso da artéria carótida interna. Essa técnica permite acesso à área petroclival anterior ao canal auditivo interno, posterior ao cavo de Meckel, inferior ao seio petroso superior e superior ao seio petroso inferior. Essa dissecção pode estender-se medialmente ao clivus pela remoção do seio petroso inferior na sincondrose petrooccipital. As extensões supratentoriais dos tumores podem ser atingidas pela secção do seio petroso superior e do tentório. Se o tumor se estende posteriormente ao canal auditivo interno ou através da linha média, o acesso translabiríntico e transcoclear oferecerá maior acesso às regiões pré-pontina e petroclival. A combinação com o acesso tipo B de Fisch pode ser usada, assim como combinações com o acesso petroso de Al Mefty e cols. ${ }^{3}$ e supratentorial infratentorial retrolabiríntico. Uma desvantagem freqüente do acesso transpetroso apical é a necessidade de secção do nervo mandibular.

\section{Sinusectomias paranasais}

Os seios paranasais podem ser invadidos em cirurgia da base do crânio para a remoção de neoplasias ou durante a realização das craniotomias. Em geral a mucosa sinusal é removida, mas eventualmente os tumores podem obrigar a remoção em bloco dos seios.

Os riscos da intrusão sinusal incluem a infecção cirúrgica e a formação de fístulas liquóricas, o que obriga à cuidadosa reconstrução e impermeabilização durante a fase de fechamento, utilizando-se freqüentemente diversos tipos de enxerto. Tais reconstruções são facilitadas quando se utilizam técnicas osteoplásticas. 
O tráfego para o andar anterior através do seio frontal permite acesso à área mediana deste compartimento. Esta mesma sinusectomia osteoplástica foi, depois, adaptada à craniotomia frontotemporoorbitozigomática completa.

Os acessos transcranianos e combinados para tumores que acometem primária ou secundariamente os seios paranasais visam sempre remoções em bloco, quando possível, e radicais, geralmente por técnicas combinadas craniofaciais. Foram discutidos procedimentos por Blacklock e cols. ${ }^{5}$, em 1989, considerando a dissecção associada da fossa infratemporal em tumores malignos.

\section{Osteotomias para o acesso infratemporal}

A fossa infratemporal é limitada anteriormente pela face posterior da maxila e pela fissura orbitária inferior, e posteriormente pelas partes timpânica e mastóidea do osso temporal. Seu teto é formado pela superfície inferior da asa maior do esfenóide e pela parte escamosa do osso temporal. Seus limites mediais são o processo pterigóide, o clivus e a superfície inferior do ápice da pirâmide. Os músculos locais são o temporal, o masseter, o digástrico e os músculos peterigóideos, estiloglosso, estilo-hióide, estilofaríngeo e tensor do véu do paladar. $\mathrm{O}$ nervo facial emerge do forame estilomastóide e divide-se em partes temporofacial e cervicofacial. Os ramos temporal e zigomático cruzam o arco zigomático sobre a fáscia superficial do músculo temporal, obrigando a dissecção interfascial.

A ressecção do arco zigomático, do côndilo da mandíbula e do assoalho da fossa craniana média aumenta a exposição do conteúdo da fossa infratemporal e das áreas naso, retro e parafaríngeas, assim como dos seios etmoidal, esfenoidal e maxilar, da artéria carótida interna, do seio cavernoso, do osso petroso e de parte da fossa craniana posterior. Terz e cols. ${ }^{60}$, em 1969, estudaram o acesso à fossa pterigóidea, mas a abordagem aos tumores da fossa infratemporal foi sistematizada por Fisch ${ }^{20}$ em 1978. Trata-se de uma abordagem póstero-lateral que requer uma osteotomia temporal extensa para se alcançar o compartimento anterior da fossa infratemporal e inclui o sacrifício do nervo mandibular e do canal auditivo.

$\mathrm{O}$ acesso pré-auricular lateral com várias modificações tem sido preconizado para a intrusão nesta região. Nessas modificações, o músculo temporal é totalmente destacado de sua inserção na fossa temporal. Tal desconexão denerva e desvasculariza a musculatura, além de esta permanecer como obstáculo à exposição cirúrgica das fossas esfenopalatina e infratemporal. A modificação de Al Mefty e cols. ${ }^{2}$ corrige parcialmente essas imperfeições, realizando, após a exposição interfascial do músculo temporal e a exposição da carótida cervical e do tronco do nervo facial, a remoção do arco zigomático, que é deslocado caudalmente em conjunto com o masseter, seguindo-se a dissecção subperiostal e a secção basal do processo coronóide da mandíbula, o que permite elevar a inserção temporal cranialmente. Podemos, então, invadir a fossa temporal até os forames redondo, oval e espinhoso, a órbita e a fossa infratemporal. Nas abordagens ao seio cavernoso, a retração temporal será minimizada. O processo coronóide pode ser novamente fixado na sua inserção, assim como o arco zigomático. Usualmente os acessos incluem cirurgias extensas póstero-laterais transtemporais, ou ântero-laterais transmaxilares, além de acessos transmandibulares.

\section{Reconstrução da base do crânio}

A reconstrução de remoções ósseas extensas da base do crânio implica impedimento da formação de fístulas de líquido cefalorraquidiano, e de bom resultado estético. Enxertos homólogos ósseos ou durais devem ser cobertos com tecido vascularizado sempre que possível.

As técnicas de reconstrução da base do crânio utilizam a reposição do tecido ósseo removido e das partes musculares e tegumentares adjacentes, além de retalhos galeais, miofasciais, musculares, de gordura subcutânea, durais e ósseos; autólogos, homólogos ou heterólogos; pediculados ou não; adjacentes ou a distância; conforme extensa literatura disponível. Podem ser usados retalhos pediculados de periósteo, músculo ou gálea.

\section{Referências}

1. AL MEFTY O: Supraorbital-pterional approach to skull base lesions. Neurosurgery 21:474-7, 1987.

2. AL MEFTY O, ANAND VK: Zygomatic approach to skull base lesions. J Neurosurg 73:668-73, 1990.

3. AL MEFTY O, FOX JL, SMITH RR: Petrosal approach for petroclival meningiomas. Neurosurgery 22:510-7, 1988.

4. AMMIRATI M, MAJ, BECKER DP, BLACK K, CHEATHAM M, BLOCH J: Transzygomatic approach to the tentorial incisura. Surgical anatomy. Skull Base Surg 2:161-5, 1992.

5. BLACKLOCK JB, WEBER RS, LEE Y, GOEFFERT H: Transcranial resection of tumors of the paranasal sinuses and nasal cavity. J Neurosurg 71:10-5, 1989.

6. BONNAL J, THIBAUT A, BROTCHI JD, BORN J: Invading meningiomas of the sphenoid ridge. J Neurosurg 53:587-9, 1980.

7. BROCK M, DIETZ H: The small fronto-lateral approach for the microsurgical treatment of intracranial aneurysms. Neurochirurgia (Stuttgart) 21:185-91, 1978. 
8. CABRERA HN, LUZIO J, PAHL FH, VELLUTINI AS, TEIXEIRA MJ, SILVA CC, ALMEIDA GMA: Tratamento dos meningiomas da asa do esfenóide por meio da craniotomia fronto-órbito-temporal. Arq Bras Neurocir (São Paulo) 4: 215-22, 1985.

9. CASANOVA R, CAVALCANTE D, GROTTING JC, VASCONEZ LO, PSILLAKIS JM: Anatomic basis for vascularized outer-table calvarial bone flaps. Plast Reconstruct Surg 78:300-8, 1986

10. CHOU SN, ORTIZ-SUAREZ HJ: Surgical treatment of arterial aneurysms of the vertebrobasilar circulation. J Neurosurg 41:671-80, 1974.

11. COPHIGNON J, GEORGE B, MARCHAC D, ROUX F: Voie transbasale élargie par mobilisation du bandeau frontoorbitaire median. Neurochirurg 29:407-10, 1983.

12. DANDY WE: Results following transcranial operative attack on orbital tumors. Arch Ophtalmol 25:191-215, 1941.

13. DELASHAW JB, TEDESCHI H, RHOTON AL: Modified supraorbital craniotomy: Technical note. Neurosurgery 30:954-6, 1992

14. DELFINI R: Craniofacial approaches for tumors involving the anterior half of the skull base. In: Samii M (ed.): Skull base surgery. Basel, Karger, 1994, pp 128-30.

15. DEROME PJ, GUIOT G: Bone problems in meningiomas invading the base of the skull. Clin Neurosurg 25:435-57, 1978.

16. DOLENC V: A combined epi and subdural direct approach to carotid - ophthalmic artery aneurysms. J Neurosurg 62:667-72, 1985.

17. DOLENC V, SKRAP M, SUSTERSIC J, SKRBEC M, MORINAA: A transcavernous - transsellar approach to the basilar tip aneurysms. Br J Neurosurg 1:251-9, 1987.

18. DRAKE CG: Bleeding aneurysms of the basilar artery: direct surgical managment in four cases. J Neurosurg v18:230-8, 1961.

19. DRAKE CG: The surgical treatment of aneurysms of the basilar artery. J Neurosurg 29:436-46, 1968.

20. FISCH U: Infratemporal fossa approach to tumors of the temporal bone and base of the skull. J Laryngol Otol 92: 949-67, 1978.

21. FUJITSU K, KUWABARA T: Zygomatic approach for lesions in the interpeducular cistern. J Neurosurg 62:430-4, 1985.

22. FUJITSU K, KUWABARA T: Orbitocraniobasal approach for anterior communicating artery aneurysms. Neurosurgery 18:367-9, 1986

23. GABIBOV GA, TANYASHIN SV, KOZLOV AV: Surgical treatment for anterior tentorial meningiomas: an experience of 40 cases (1982-92). In Samii M (ed.): Skull base surgery. Basel, Karger, 1994, pp 194-8.

24. GLASSCOCK ME III, MILLER GW, DRAKE FD, KANOK MM: Surgery of the skull base. Laryngoscope 88:905-23, 1978.

25. GLEESON MJ: Resection of cystic lesions at the petrous apex. In Samii M (ed.): Skull base surgery. Basel, Karger, 1994, pp 953-6.

26. HAKUBA A, LIU S, NISHIMURA S: The orbitozygomatic infratemporal approach: a new surgical technique. Surg Neurol 26:271-6, 1986.

27. HAKUBAA, NISHIMURA S, JANG BJ: A combined retroauricular and preauricular transpetrosal-transtentorial approach to clivus meningiomas. Surg Neurol 30:108-16, 1988.

28. HAMMER B, PREIN J, GRATZL O, HUSAG L, PROBST $R$ : Tumors involving the orbit: technical notes to the frontotemporal-orbitozigomatic approach. In Samii M (ed.): Skull base surgery. Basel, Karger, 1994, pp 258-61.
29. HASSLER W, EGGERT HR: Extradural and intradural microsurgical approaches to lesions of the optic canal and the superior orbital fissure. Acta Neurochir (Wien) 74:87-93, 1985.

30. IKEDA K, YAMASHITA J, HASHIMOTO M, FUTAMI K: Orbitozygomatic temporopolar approach for high basilar tip aneurysm associated with a short intracranial internal carotid artery: a new surgical approach. Neurosurgery 28:105-10, 1991.

31. JANE JA, PARK TS, POBERESKIN LH, WINN HR, BUTLER $A B$ : The supraorbital approach: technical note. Neurosurgery 2:537-42, 1982.

32. JOAQUIM MAS, ALMEIDA GGM, PITELLI SD, VELLUTINI E: Abordagens órbito-zigomática e fronto-têmporo-orbitozigomática. Arq Bras Neurocir (São Paulo) 6:157-64, 1987.

33. KAWASE T, SHIOBARA R, TOYA S: Anterior transpetrosaltranstentorial approach for sphenopetroclival meningiomas: surgical method and results in 10 patients. Neurosurgery 28:869-76, 1991.

34. KOBAYASHI S, SUGITA K, NAKAGAWA F: An approach to a basilar aneurysm above the bifurcation of the internal carotid artery. Case report. J Neurosurg 59:1082-4, 1983.

35. LESOIN F, THOMAS CE III, PELLERIN P, VILLETTE L, AUTRICQUE A, JAMIN M: An orbital-zygomatic-malar bone flap approach: A technical note. Acta Neurochir (Wien) 83:154-6, 1986.

36. MAROON JC, KENNERDELL JS: Tumors of the orbit. In Wilkins R, Rengashary S (ed.): Neurosurgery. New York, McGraw-Hill, 1985, pp 964-76.

37. MC DERMOTT MW, DURITY FA, ROOTMAN J, WOODHURST WB: Combined frontotemporal-orbitozygomatic approach for tumors of the sphenoid wing and orbit. Neurosurgery 26:107-16, 1990.

38. OIKAWA S, MIZUNO M, MURAOKA S, KOBAYASHI S: Retrograde dissection of the temporalis muscle preventing muscle atrophy for pterional craniotomy. J Neurosurg 84:297-9, 1996

39. ORIGITANO TC, ANDERSON DE, TARASSOLI Y, REICHMAN OH, AL MEFTY O: Skull base approaches to complex cerebral aneurysms. Surg Neurol 40:339-46, 1993.

40. PELLERIN P, LESOIN F, DHELLEMMES P, DONAZZAN M, JOMIN M: Usefulness of the orbitofrontomarlar approach associated with bone reconstruction for frontotemporosphenoid meningeomas. Neurosurgery 15:715-8, 1984.

41. PITELLI SD, ALMEIDA GGM, NAKAGAWA EJ, MARCHESE AJT, CABRAL ND: Basilar aneurysm surgery: The subtemporal approach with section of the zygomatic arch. Neurosurgery 18: 125-8, 1986.

42. POLETTI CE: A temporal approach to anterior communicating artery aneurysms: technical note. J Neurosurg 71:144-6, 1989.

43. POMPILI A, DEROME PJ, VISOTA, GUIOT G: Hyperostosing meningiomas of the sphenoid ridge - Clinical features, surgical therapy and longterm observations. Review of 49 cases. Surg Neurol 17:411-6, 1982.

44. RUBINI GJ, RODTS GE, HOLLAND ML, BECKER DP: The transzygomatic approach to the middle fossa. In: Samii M (ed.) Skull base surgery. Basel, Karger, 1994, pp 513-7.

45. SAMII M, AMMIRATI M: The combined supra-infratentorial presigmoid sinus avenue to the petroclival retion. Surgical technique and clinical applications. Acta Neurochir (Wien) 9:6-12, 1988.

46. SAMY LL, GIRGIS IH: Transzygomatic approach for nasopharyngeal fibromata with extrapharyngeal extension. J Laryngol Otol 79:782-95, 1965.

47. SANO K: Temporo-polar approach to aneurysms of the basilar artery at and around the distal bifurcation: technical note. Neurol Res 2:361-7, 1980. 
48. SEKHAR LN, MOLLERAR: Operative managment of tumors involving the cavernous sinus. J Neurosurg 64:879-89, 1986.

49. SEKHAR LN, SEN CN: Surgical treatment of tumors involving the cavernous sinus. In Schmidek HH, Sweet WH (ed.): Operative neurosurgical techniques. Ed 3. Philadelphia, WB Saunders, 1995. pp 334-45.

50. SEKHAR LN, SCHRAMM VL Jr, JONES NF: Subtemporal preauricular infratemporal fossa approach to large lateral and posterior cranial base neoplasms. J Neurosurg 67:48899, 1987.

51. SEKHAR LN, NANDA A, SEN CN, SNYDERMAN CN, JANECKA IP: The extend frontal approach to tumors of the anterior middle and posterior skull base. J Neurosurg 76:198-206, 1992.

52. SENGUPTA RP: Posterior circulation aneurysms: surgical approaches. In Samii M (ed.): Skull base surgery. Basel, Karger, 1994, pp 690-5.

53. SINDOU M, ALAYWAN M: La dépose orbitaire et/ou zygomatique dans l'abord des lesions proches de la base du crâne. Technique chirurgicale, étude anatomique et analyse d'une serie de 24 cas. Neurochirurg 36:225-33, 1990.

54. SINDOU M, FOBE JL: Removal of the roof of the external auditory meatus in approaching the tentorial notch through a low temporal craniotomy. J Neurosurg 74:520-2, 1991.

55. SMITH RR, AL MEFTY O, MIDDLETON T: An orbitocranial approach to complex aneurysms of the anterior circulation. Neurosurgery 24:385-91, 1989.

56. SPETZLER RF, DASPIT CP, PAPPAS CTE : The combined supra and infratentorial approach for lesions of the petrous and clival regions: Experience with 46 cases. J Neurosurg 76:588-99, 1992.

57. SUGITA K, KOBAYASHI S, SHINTANI A, MUTSUGA N: Microneurosurgery for aneurysms of the basilar artery. J Neurosurg 51:615-20, 1979.
58. TANAKAY, KOBAYASHIS, SUGITAK, GIBO H, KYOSHIMA K, NAGASAKI T: Characteristics of pterional routes to basilar bifurcation aneurysm. Neurosurgery 36:533-40, 1995.

59. TEDESCHI H, RHOTON AL: Lateral approaches to the petroclival region. Surg Neurol 41:180-216, 1994.

60. TERZ JJ, ALKSNE JF, LAWRENCE W Jr: Craniofacial resection for tumor invading the pterygoid fossa. Am J Surg 118:732-40, 1969.

61. UTTLEY D, ARCHER DJ, MARSH HT, BELL BA: Improved access to lesions of the central skull base by mobilization of the zygoma: experience with 54 cases. Neurosurgery 28:99-104, 1991.

62. YASARGIL MG: Interfascial pterional (frontotemporosphenoidal) craniotomy. In Yasargil MG (ed): Microsurgery. New York, Thieme-Stratton, 1984, v.1, pp 215-33.

63. YASARGIL MG, FOX JL: The microsurgical approach to intracranial aneurysms. Surg Neurol 3:7-13, 1975.

64. YASARGIL MG, FOX JL, RAY MW: The operative approach to aneurysms of the anterior comunicating artery. Adv Techn Stand Neurosurg 2:113-70, 1975.

Original recebido em dezembro de 2006

Aceito para publicação em setembro de 2007

\section{Endereço para correspondência}

Marcos Augusto Stávale Joaquim

Alameda Campinas, $1.360-16^{\circ}$ andar

01404-002 - São Paulo, SP

E-mail: marcos.stavale@terra.com.br 